\title{
OTC Derivatives and Global Economic Activity: An Empirical Analysis
}

\author{
Gordon Bodnar, Jonathan Fortun and Jaime Marquez * \\ Johns Hopkins School of Advanced International Studies, The Johns Hopkins University, \\ Washington, DC 20036, USA; bodnar@jhu.edu (G.B.); jfortun@iif.com (J.F.) \\ * Correspondence: jmarque1@jhu.edu \\ Academic Editor: Donald Lien \\ Received: 6 April 2017; Accepted: 7 June 2017; Published: 14 June 2017
}

\begin{abstract}
That the global market for derivatives has expanded beyond recognition is well known. What is not know is how this market interacts with economic activity. We provide the first empirical characterization of interdependencies between OECD economic activity and the global OTC derivatives market. To this end, we apply a vector-error correction model to OTC derivatives disaggregated across instruments and counterparties. The results indicate that with one exception, the heterogeneity of OTC contracts is too pronounced to be reliably summarized by our measures of economic activity. The one exception is interest-rate derivatives held by Other Financial Institutions.
\end{abstract}

Keywords: over the counter derivatives; economic activity; cointegration

\section{Introduction}

That the global market for Over the Counter (OTC) derivatives has expanded significantly is well known: ${ }^{1}$ Notional values reported by the Bank of International Settlements (BIS) have increased from about $\$ 100$ trillion in 1998 to $\$ 630$ trillion in 2014. To some observers, such an expansion is the natural result of a well functioning market:

"Why do we see this great success of financial futures and the financial futures industry? The reasons are the same as the reasons for the successful growth of any other industry: The industry is offering a product that people want. To show that they want it, they are willing to pay for it. What is the product that the world seems to want and that is so much in demand? The answer is insurance. The world wants insurance against price risk." (Miller (1997), p. 79)

So it comes as no surprise that, based on the survey of global business of Bodnar et al. (2011), firms report that protection from price surprises is the most important reason for using OTC derivatives:

\begin{tabular}{lcc}
\hline & \multicolumn{2}{c}{ Rating of Importance } \\
\hline Objective & Very Important & Not Important \\
\hline Avoid losses from price surprises & $50 \%$ & $3 \%$ \\
Expectations from shareholders & $41 \%$ & $3 \%$ \\
Increase expected future cash flows & $38 \%$ & $3 \%$ \\
\hline
\end{tabular}

Source: Bodnar et al. (2011).

1 Key features of OTC derivatives: Contracts are tailored to counterparties' needs, counterparties do not post margins, contracts are not regulated: Only periodic disclosure required; no rules on who can hold derivatives; no limits on holdings. See the explanations provided by the Bank of International Settlements (BIS): https://www.bis.org/statistics/about derivatives_stats.htm?m=6\%7C32\%7C639. 
However, as Bodnar et al. (2011) report, firms also use OTC derivatives for different purposes:

- $\quad$ to exploit latent economies of scale (Miller (1997))

- $\quad$ to address the mismatch in interest-rate sensitivities in firms' balance sheets

- to diversify assets in credit institutions, which allows the extension of bank credits to firms (Morrison (2005))

- $\quad$ to protect lenders from borrowers' defaults.

For example, as Stegman (2014) notes

“... Historically, securitization has played a valuable role in housing finance. By allowing interest rate and credit risks to be allocated efficiently among investors with varying risk appetites, it expanded access to credit for many credit-qualified Americans. ..."2

This intuition is confirmed by the substantial literature on the effects of derivatives on economic activity at micro level. ${ }^{3}$ To be sure, however, derivatives do not do magic but they deliver the same price protection at a fraction of the cost of the alternative and thus they release resources that can be used to increase production.

However, as currently practiced and modeled, derivative contracts affecting a firm's production assume that market interest rates and exchange rates faced by the firm are independent from changes in the firm's output. ${ }^{4}$ That logic does not extend to the aggregate level: an increase in aggregate economic activity will affect interest rates and exchange rates, all of which feed into the decision to carry out hedging. Thus the increase in derivatives trade that is promoting aggregate economic activity is also inducing changes in the givens of those derivative contracts. ${ }^{5}$

These observations suggest the existence of an interdependency between OTC derivatives and economic activity for which no empirical characterization is available from the literature. ${ }^{6}$ This neglect is relevant for assessing the reliability of current efforts to craft regulations on derivative trading. The argument in favor of regulation, made by Stulz, is by analogy: Derivative markets are akin to airline travel—dangerous and in need of regulation; Dudley (2013) ${ }^{7}$ and Lew (2013) ${ }^{8}$ discuss the extent and manner in which the OTC market for derivatives might be regulated. The argument against regulation is that derivative contracts are like marriage contracts-highly tailored to circumstances that cannot be standardized across sectors. Greenspan (1998) ${ }^{9}$ and Summers (1998) ${ }^{10}$ argue strongly against regulation. But neither side offers evidence supporting their beliefs. ${ }^{11}$ Addressing these contrasting views is relevant for a regulatory process that seeks to avoid unintended consequences and hinge on the nature of the association between derivative trading and economic growth. In other words, one needs

2 Dr. Michael Stegman before a Bipartisan Policy Center Panel “Reigniting the Private Label Mortgage-backed Securities Market" http://www.treasury.gov/press-center/press-releases/Pages/j12634.aspx (accessed on 15 September 2014).

3 See Hopper (1995), Miller (1997), Still (1997), Smithson (1998), Summers (1998), Greenspan (1998), Morrison (2005), Sundaram (2012).

4 (Smithson 1998, p. 229) and Merton (1973) relax the assumption of a constant interest rate in the Black-Scholes model. However, Merton did not endogenize the interest rate as a function of the aggregate derivative contracts.

5 Specifically, it is not enough to say that firms may use a forecast of GDP or interest rates. What is of interest is how those forecasts will react to changes in policies or other shocks. In addition, if they do and the associated forecast revision leads to a change in the hedging strategy, then it will represent the effect of economic activity on derivatives.

6 Interest in the finance-growth link is not new. What is new here is the focus on OTC derivatives.

7 http://www.ny.frb.org/newsevents/speeches/2013/dud130912.html.

8 http://www.treasury.gov/press-center/press-releases/Pages/j12242.aspx.

http:/ / www.federalreserve.gov/boarddocs/testimony/1998/19980730.htm.

10 https://www.treasury.gov/press-center/press-releases/Pages/rr2616.aspx.

11 The BIS' Macroeconomic Assessment Group on Derivatives published a report (BIS 2013) finding that regulations on derivatives will have a minimal effect on economic activity (BIS 2013, p. 4). However, these calculations do not recognize the feedback effect from GDP to derivatives. BIS (2013) empirical work relies on models that treat the effect of income on derivatives as given. The idea is that deriviatives affect the cost of capital and therefore investment and therefore GDP. But again this work assumes that one can treat economic activity as not mattering for derivatives. 
to assess whether an increase in OTC derivatives promotes economic activity, whether an expansion in economic activity promotes the derivatives market, or whether they are jointly determined.

We provide the first empirical characterization of interdependencies between OECD economic activity and the global OTC derivatives market. We do so by recognizing the heterogeneity of contracts counterparties and instruments. Specifically, we apply a vector-error correction model to OTC derivatives disaggregated across instruments and counterparties. The results indicate that with one exception, the heterogeneity of OTC contracts is too pronounced to be reliably summarized by our measures of economic activity. The one exception is interest-rate derivatives held by Other Financial Institutions (70 percent of aggregate). For this category, we find that they are jointly determined. Further, we also find that the effects of changes in OECD's GDP on OTC derivatives are much larger than the effects of derivatives on that GDP. Indeed, a hypothetical 10\% contraction in OTC global derivatives lowers real GDP by 0.2 percent after 12 years, which is small relative to the contraction of GDP during the Great Recession. Finally, we offer a preliminary estimate of the contribution of speculative behavior in the run-up to the 2008 financial crisis.

\section{The Evolution of Global OTC Derivatives}

Our focus is on the semi-annual data on OTC derivative contracts reported by the BIS. Because the BIS' data collection efforts do not always permit the precise allocation of every contract across counterparties or instruments, the BIS reports the Allocated (denoted here as D) and Unallocated aggregates for the notional value of contracts (Figure 1):

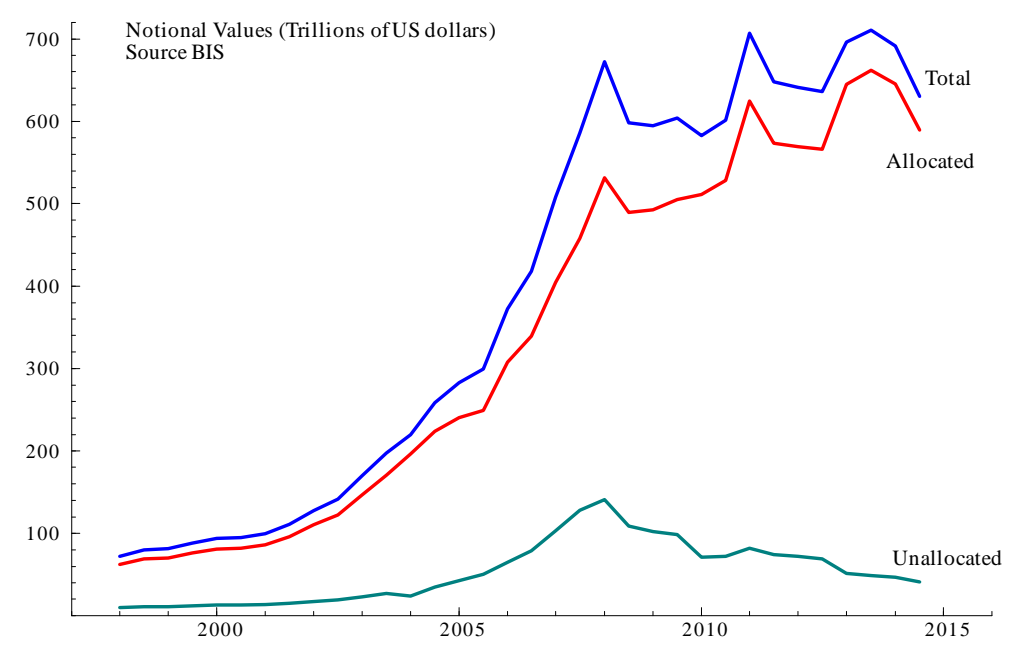

Figure 1. Aggregate OTCderivatives.

Note that the category of Unallocated derivatives represents a small and declining share of total derivatives. Unallocated derivatives are estimated as a pre determined percentage of the measured activity from reporting entities. That percentage is only being updated every 3 years based upon the triennial survey. ${ }^{12}$

An important question is whether the composition of the allocated OTC derivatives across Instruments and Counterparties has changed over time. Following the BIS' definitions, we consider three counterparties: Nonfinancial, Other Financial, and Dealers. Of these, contracts held by Other Financial counterparties account for the largest and rising share of OTC derivatives (Figure 2). Note, however, that through 2005 dealers were equally important but have declined since then both in absolute and relative terms.

12 Thanks to Denis Pêtre from the BIS for clarifying the source of the unallocated derivatives. 


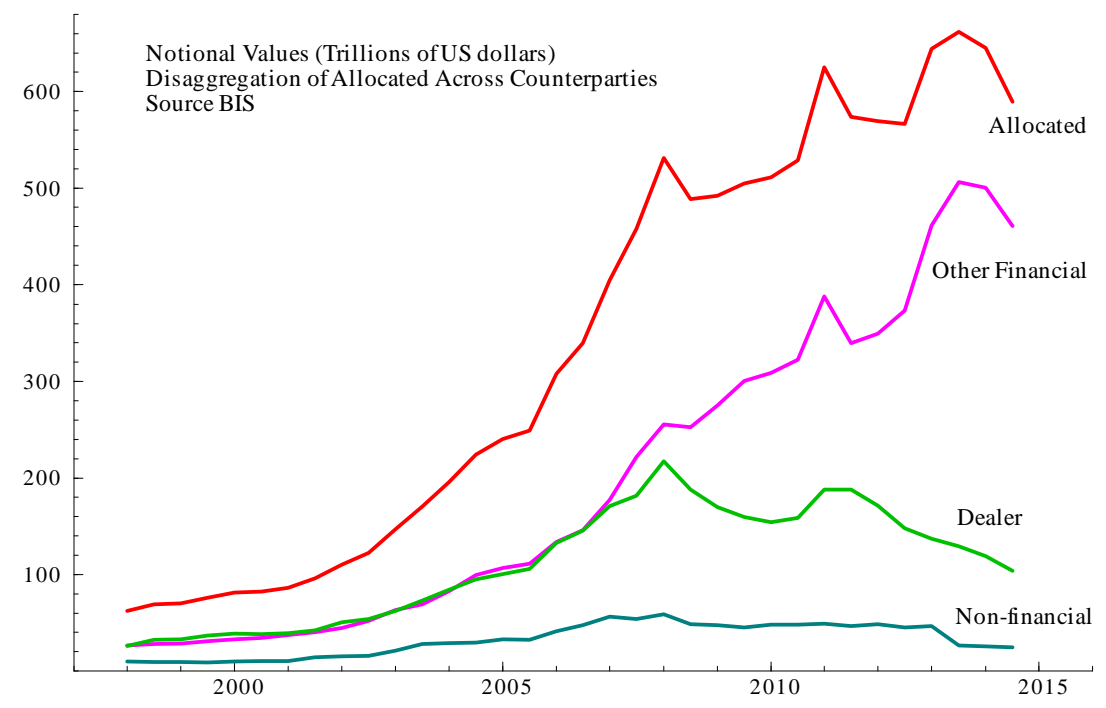

Figure 2. OTCd erivatives disaggregated Across Counterparties.

Again, following the BIS' definitions, we consider three derivative instruments: Interest Rates, Foreign Exchange, and Equity Linked; a fourth category is Commodity but we exclude it because it is small. ${ }^{13}$ Of these instruments, Interest-Rate derivatives account for the largest and rising share of OTC derivatives (Figure 3).

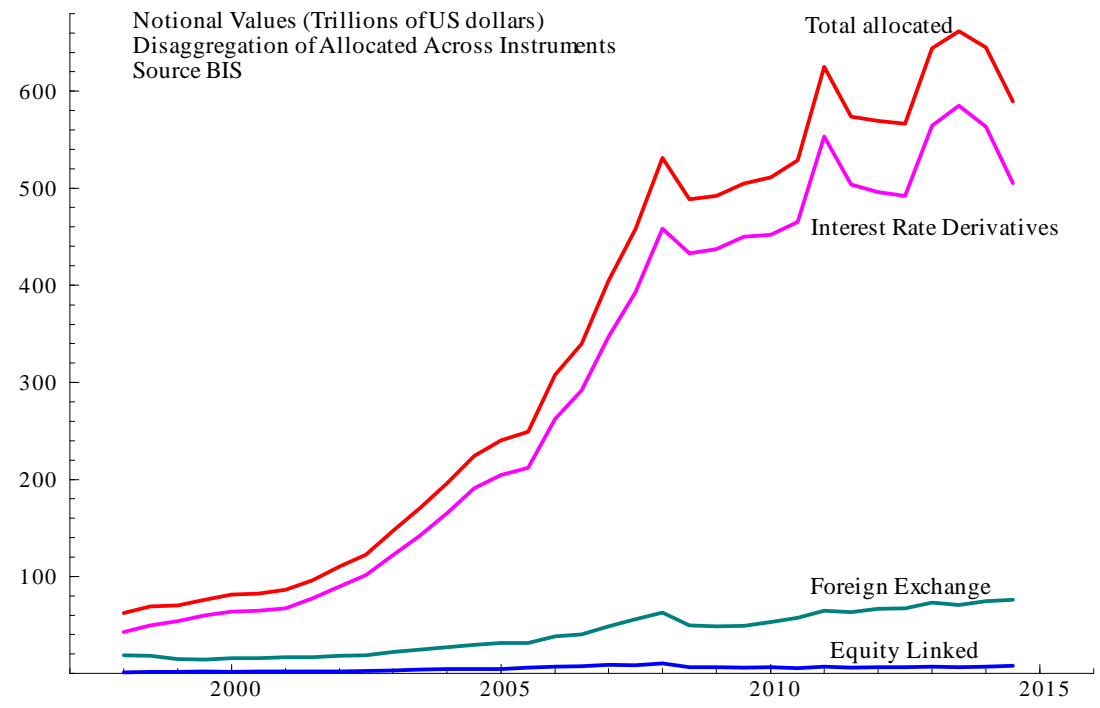

Figure 3. OTC derivatives disaggregated Across Instruments.

When viewed together, Figures 2 and 3 suggest that treating OTC derivatives as a single homogenous financial instrument involves a loss of information. This loss consists of the unsuitability of using evidence obtained for the aggregate to carry out inferences for the components of that aggregate. To emphasize this loss, our analysis disaggregates derivatives by instrument and counterparty and we use this disaggregation for characterizing the relation between OTC derivatives and economic activity. We now turn to this question.

13 Our data do not include Credit Default Swaps. The BIS treats this category separately and are a small fraction of the total; see http://www.bis.org/publ/otc_hy1705.pdf. 


\section{Empirical Analysis}

\subsection{Measurement}

Our raw data contains seven instruments, indexed by $j$, and three counterparties, indexed by $i$. Thus $D_{j i}$ represents notional contracts of the $j t h$ instrument held by the ith counterparty. The resulting data matrix is

\begin{tabular}{lllccc}
\hline & & \multicolumn{3}{c}{ Counterparties $(i)$} \\
\cline { 3 - 5 } & & & Non-Financial & Other Financial & Dealers \\
\hline \multirow{3}{*}{ Foreign Exchange } & Currency Swaps & $D_{11}$ & $D_{21}$ & $D_{31}$ \\
& \multirow{2}{*}{ Instruments $(j)$} & Options & $D_{12}$ & $D_{22}$ & $D_{32}$ \\
\cline { 3 - 6 } & \multirow{2}{*}{ Interest Rate } & Interest Rate Swaps & $D_{13}$ & $D_{23}$ & $D_{33}$ \\
& & Options & $D_{14}$ & $D_{24}$ & $D_{34}$ \\
\cline { 3 - 6 } & FRAs & $D_{15}$ & $D_{25}$ & $D_{35}$ \\
\cline { 3 - 6 } & \multirow{2}{*}{ Equity Linked } & Forwards and Swaps & $D_{16}$ & $D_{26}$ & $D_{36}$ \\
& Options & $D_{17}$ & $D_{27}$ & $D_{37}$ \\
\hline
\end{tabular}

Relying on the BIS to address our question involves two data adjustments: converting swaps and forwards into cash-flow equivalents and expressing derivatives in real terms.

Cash-Flow Equivalents Because movements in the notional values of swaps and forwards have a net present value of zero, one could argue that sole reliance on these notional values is not ideal for examining the interdependencies between OTC derivatives and economic activity. Thus, for these instruments, we adjust their notional values to get their cash-flow equivalent as the product of notional values for swaps and forwards and a 5-year moving average of the 5-year swap rate ( $R$, as a fraction). ${ }^{14}$ The resulting data matrix becomes:

\begin{tabular}{llllll}
\hline & & \multicolumn{3}{c}{ Counterparties $(i)$} \\
\cline { 3 - 5 } & & & Non-Financial & Other Financial & Dealers \\
\hline \multirow{3}{*}{ Foreign Exchange } & Currency Swaps & $D_{11} \cdot R$ & $D_{21} \cdot R$ & $D_{31} \cdot R$ \\
\cline { 3 - 5 } & & Options & $D_{12}$ & $D_{22}$ & $D_{32}$ \\
\cline { 3 - 5 } & \multirow{2}{*}{ Intruments $(j)$} & $D_{13} \cdot R$ & $D_{23} \cdot R$ & $D_{33} \cdot R$ \\
& & Interest Rate Swaps & $D_{24}$ & $D_{34}$ \\
\cline { 3 - 5 } & Equate & $D_{14}$ & $D_{25}$ & $D_{35}$ \\
\hline \multirow{2}{*}{ Equity Linked } & FRAs & $D_{15}$ & $D_{26} \cdot R$ & $D_{36} \cdot R$ \\
& Forwards and Swaps & $D_{16} \cdot R$ & $D_{27}$ & $D_{37}$ \\
\hline
\end{tabular}

We then consolidate contracts across instruments for each counterparty. For example, foreign-exchange contracts held by Non-financial counterparties, $D_{f x, n f}^{c}$, are measured as

$$
D_{f x, n f}^{c}=D_{11} \cdot R+D_{12}
$$

The resulting matrix of adjusted derivatives is shown in Table 1:

14 As one of the referees points out, further work is needed in this area. Importantly, there is no universally accepted method for converting notional values into cash-flow equivalents. We examined, however, the alternative of using the notional values as reported. The statistical properties of the associated models violate key assumptions such as residuals being white noise. Finding that ignoring adjustments leads to poor reliability does not automatically imply that our adjustment is correct but, we argue, it is better than the alternative. Specifically, given that the swap interest rate is influenced by economic fundamentals, we expect the movements in the adjusted series to embody economic information. 
Table 1. Disaggregation of OTC Derivatives by Counterparty and Instrument.

\begin{tabular}{lcccc}
\hline & \multicolumn{4}{c}{ Counterparties } \\
\cline { 2 - 5 } & Non-Financial & Other Financial & Dealers & Total \\
\hline \multicolumn{1}{c}{ Instruments } & & & \\
\hline Foreign Exchange & $D_{f x, n f}^{c}$ & $D_{f x, o f}^{c}$ & $D_{f x, d}^{c}$ & $D_{f x}^{c}$ \\
Interest Rate & $D_{i r, n f}^{c}$ & $D_{i r, o f}^{c}$ & $D_{i r, d}^{c}$ & $D_{i r}^{c}$ \\
Equity-linked & $D_{e l, n f}^{c}$ & $D_{e l, o f}^{c}$ & $D_{e l, d}^{c}$ & $D_{e l}^{c}$ \\
Total & $D_{n f}^{c}$ & $D_{o f}^{c}$ & $D_{d}^{c}$ & $D^{c}$ \\
\hline
\end{tabular}

Note that the matrix includes the totals across instruments and counterparties; these totals are computed as

By Counterparty

$$
\begin{array}{ll}
\text { Non-financial } & D_{n f}^{c}=\left(D_{11}+D_{13}+D_{16}\right) \cdot R+D_{12}+D_{14}+D_{15}+D_{17} \\
\text { Other financial } & D_{o f}^{c}=\left(D_{21}+D_{23}+D_{26}\right) \cdot R+D_{22}+D_{24}+D_{25}+D_{27} \\
\text { Dealer } & D_{d}^{c}=\left(D_{31}+D_{33}+D_{36}\right) \cdot R+D_{32}+D_{34}+D_{35}+D_{37}
\end{array}
$$

By Instrument

$$
\begin{aligned}
& \text { Foreign exchange } \quad D_{f x}^{c}=\left(D_{11}+D_{21}+D_{31}\right) \cdot R+D_{12}+D_{22}+D_{32} \\
& \text { Interest-rate } \quad D_{i r}^{c}=\left(D_{13}+D_{23}+D_{33}\right) \cdot R+D_{14}+D_{15}+D_{24}+D_{25}+D_{34}+D_{35} \\
& \text { Equity-linked } \quad D_{\text {el }}^{c}=\left(D_{16}+D_{26}+D_{36}\right) \cdot R+D_{17}+D_{27}+D_{37} \\
& \text { Aggregate } \quad D^{c}=D_{n f}^{c}+D_{o f}^{c}+D_{d}^{c}=D_{f x}^{c}+D_{i r}^{c}+D_{e l}^{c}
\end{aligned}
$$

We now compare the notional values and cash-flow equivalents. Figure 4 focuses on interest-rate contracts disaggregated across counterparties; Figure 5 focuses on foreign-exchange contracts; Figure 6 is for counterparties aggregated across instruments.
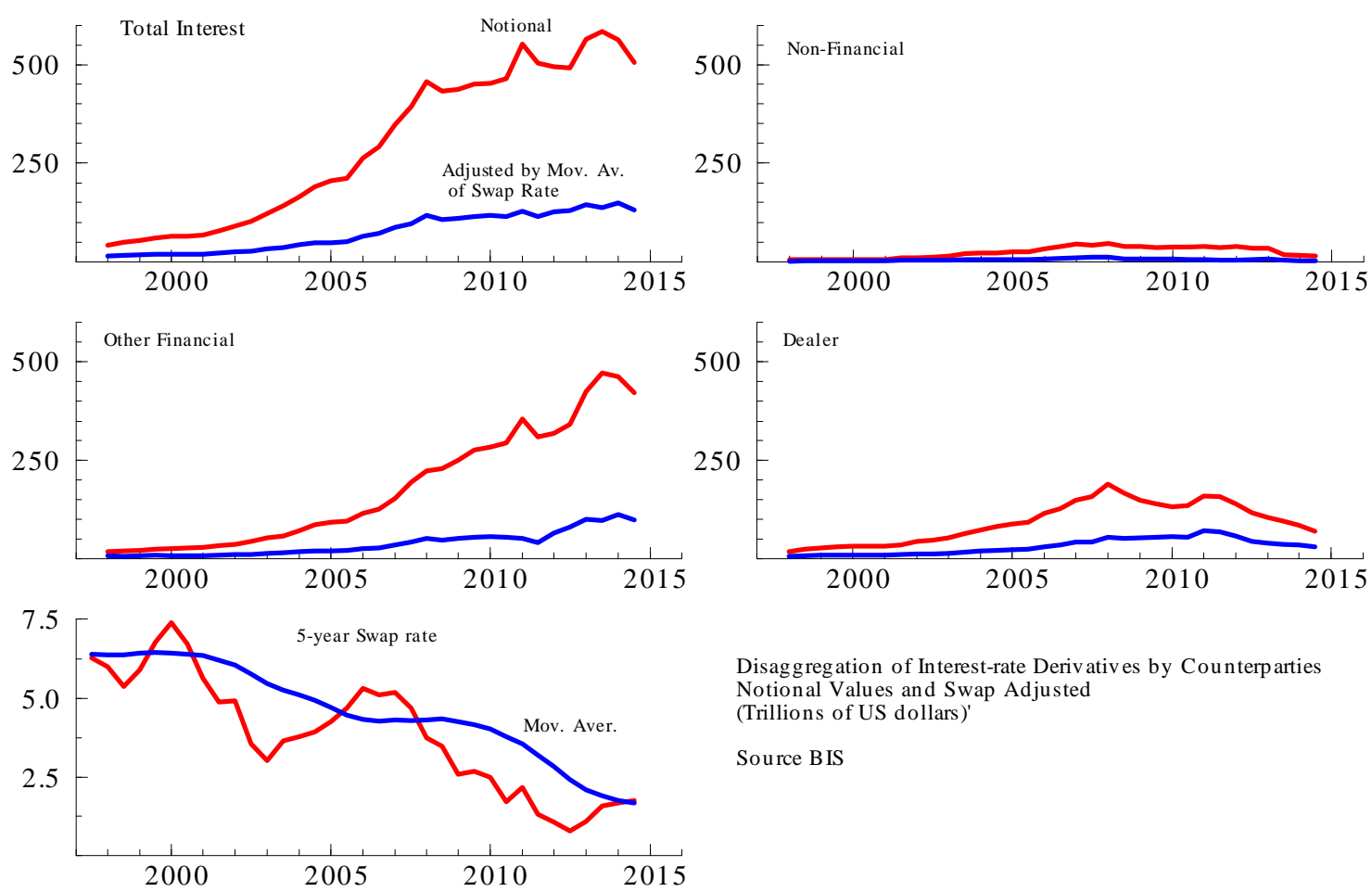

Disagg regation of Interest-rate Derivatives by Counterparties Notional Values and Swap Adjusted (Trillions of US dollars)'

Source BIS

Figure 4. Interest Rate contracts by counterparties: notional and adjusted. 

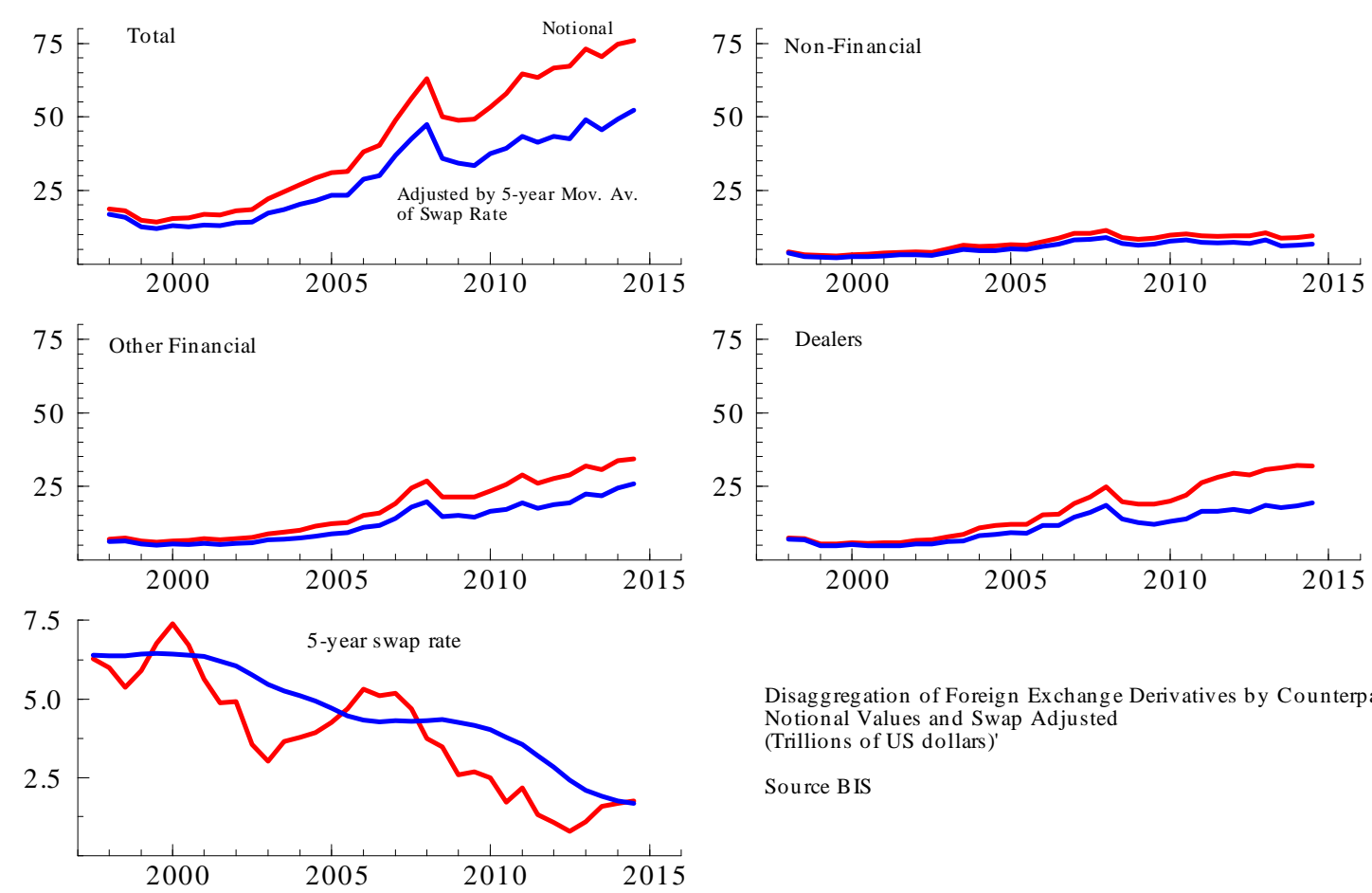

Disagg regation of Foreign Exchange Derivatives by Counterparties Notional Values and Swap Adjusted (Trillions of US dollars)'

Source BIS

Figure 5. Foreign exchange contracts by counterparties: notional and adjusted.
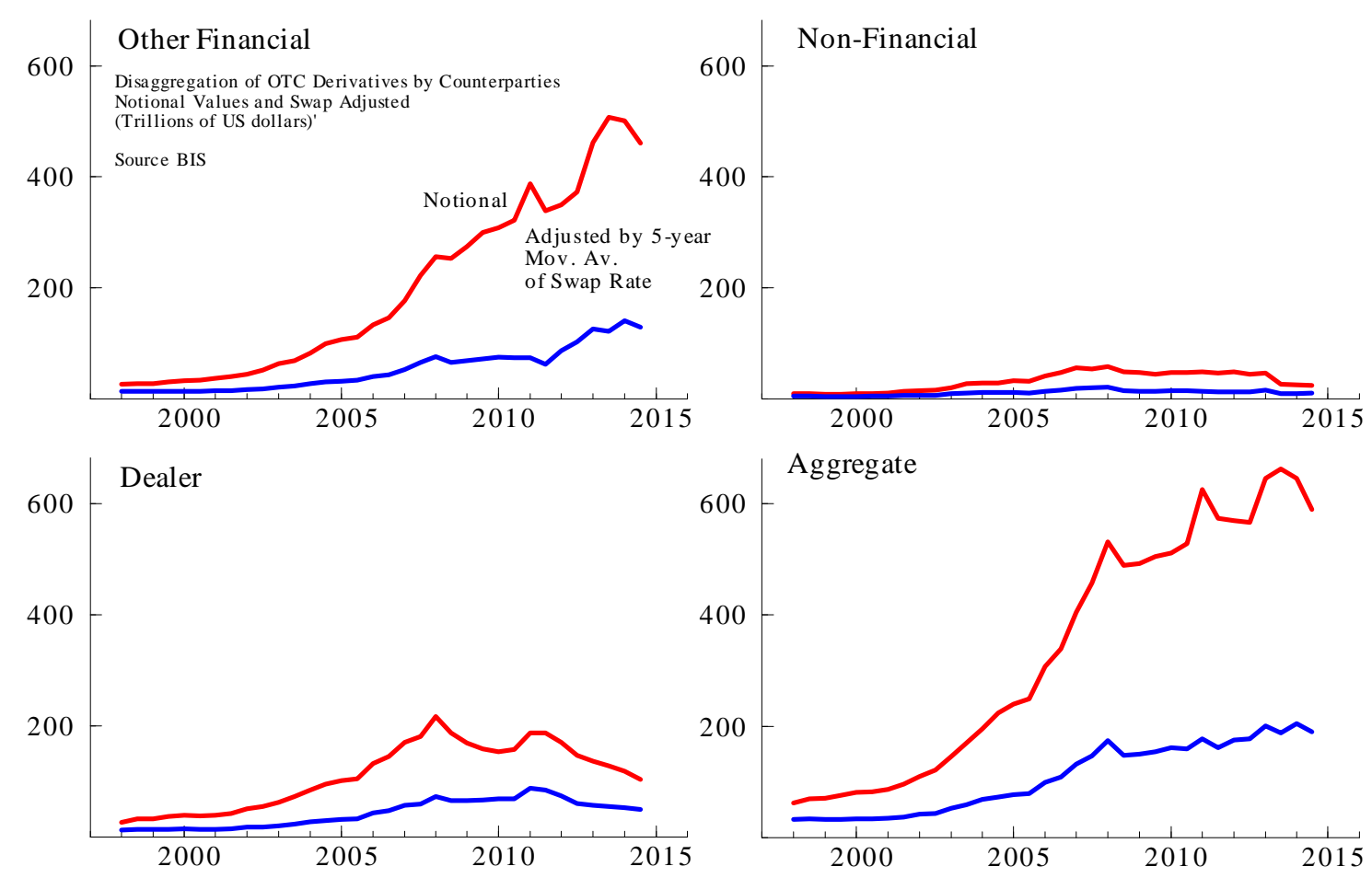

Figure 6. OTC aggregate derivatives by counterparties: notional and adjusted.

These comparisons reveal substantial differences between notional and cash-flow values. This difference is owed to two factors. The first one is the increased importance of swaps. The second one is the secular decline in the 5-year moving average of the 5-year swap rate. Note, however, that 
there are exceptions to this pattern. For example, the difference is negligible for OTC derivatives with a nonfinancial counterparty.

Expressing Derivatives in Real Terms To characterize empirically the interdependencies between economic activities and OTC derivatives, we need to express the $D^{c} s$ in real terms. To this end, we deflate the cash-flow adjusted dollar value of derivatives by the OECD's GDP deflator expressed in US dollars:

$$
d_{j i}^{c}=D_{j i}^{c} /\left[\frac{P^{f}}{E_{\frac{f x}{\$}}}\right],
$$

where $d_{j i}^{c}$ is the cash-flow adjusted derivatives, in real terms, of the $j t h$ instrument by the ith counterparty; $P_{t}^{f}$ is the OECD's GDP deflator; and $E_{\frac{f x}{\Phi}}$ nominal effective value of the U.S. dollar (fx/\$) for major currencies. Our focus is on the modeling of the relation between $d_{j i}^{c}$ and economic activity.

\subsection{Unconditional Correlations}

Figure 7 shows the association between the total real OTC derivatives, $d^{c}$, and two measures of economic activity, denoted as $a$ : Real GDP and Real Exports of Goods and Services. That there is a tendency for the two series to move in tandem is clear. As an alternative perspective, we include scatter plots with two least-squares lines-one for each half of the sample. We argue that if the regressions line does not change appreciably to changes in the sample, then the implied correlation is deemed reliable: one can reliably predict the observations for one half of the sample using the relation from the other half of the sample.

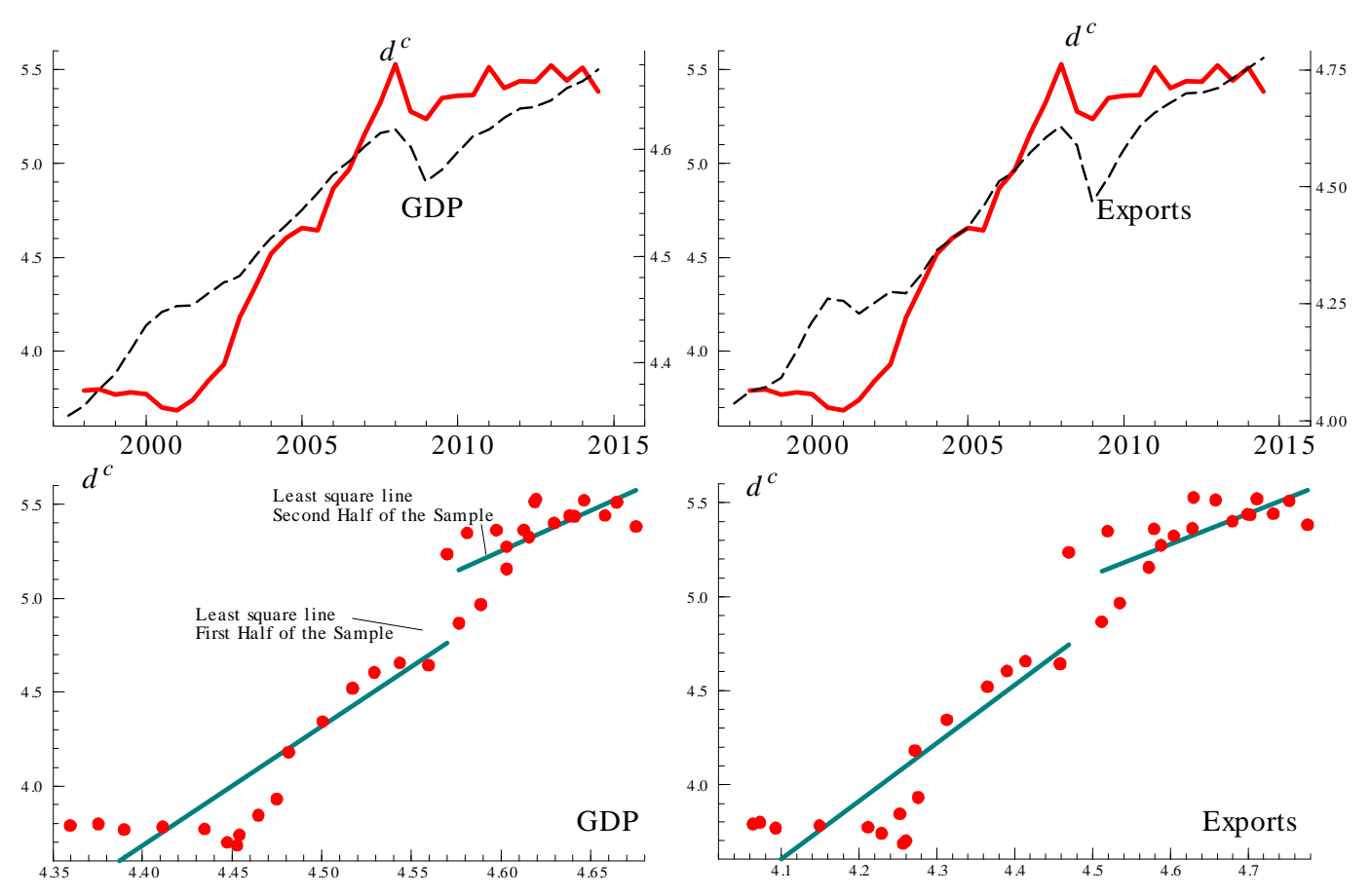

Figure 7. OTC Derivatives in real terms and Economic Activity.

Inspection of the data suggests a direct association between total real OTC derivatives and economic activity but the associated correlation is sensitive to which sample one uses, especially if one uses exports as the measure of economic activity.

To investigate whether this result owes to the substantial heterogeneity of OTC derivatives across either counterparties or instruments, Figures 8-15 report the pairwise unconditional correlations for each counterparty and instrument grouping. Specifically, we use 
- $\quad 2$ measures of economic activity " $a$ " (Real GDP and Real Exports of goods and services)

- 4 alternative counterparties (Non-Financial, Other Financial, Dealers, and Aggregate)

- 2 instruments: (Foreign-Exchange derivatives and Interest-Rate derivatives).

We show scatter plots for

- OTC derivatives aggregated across counterparties against either GDP or exports

- OTC derivatives aggregated across instruments against either GDP or exports

- OTC derivatives by instrument and counterparty against either GDP or exports.
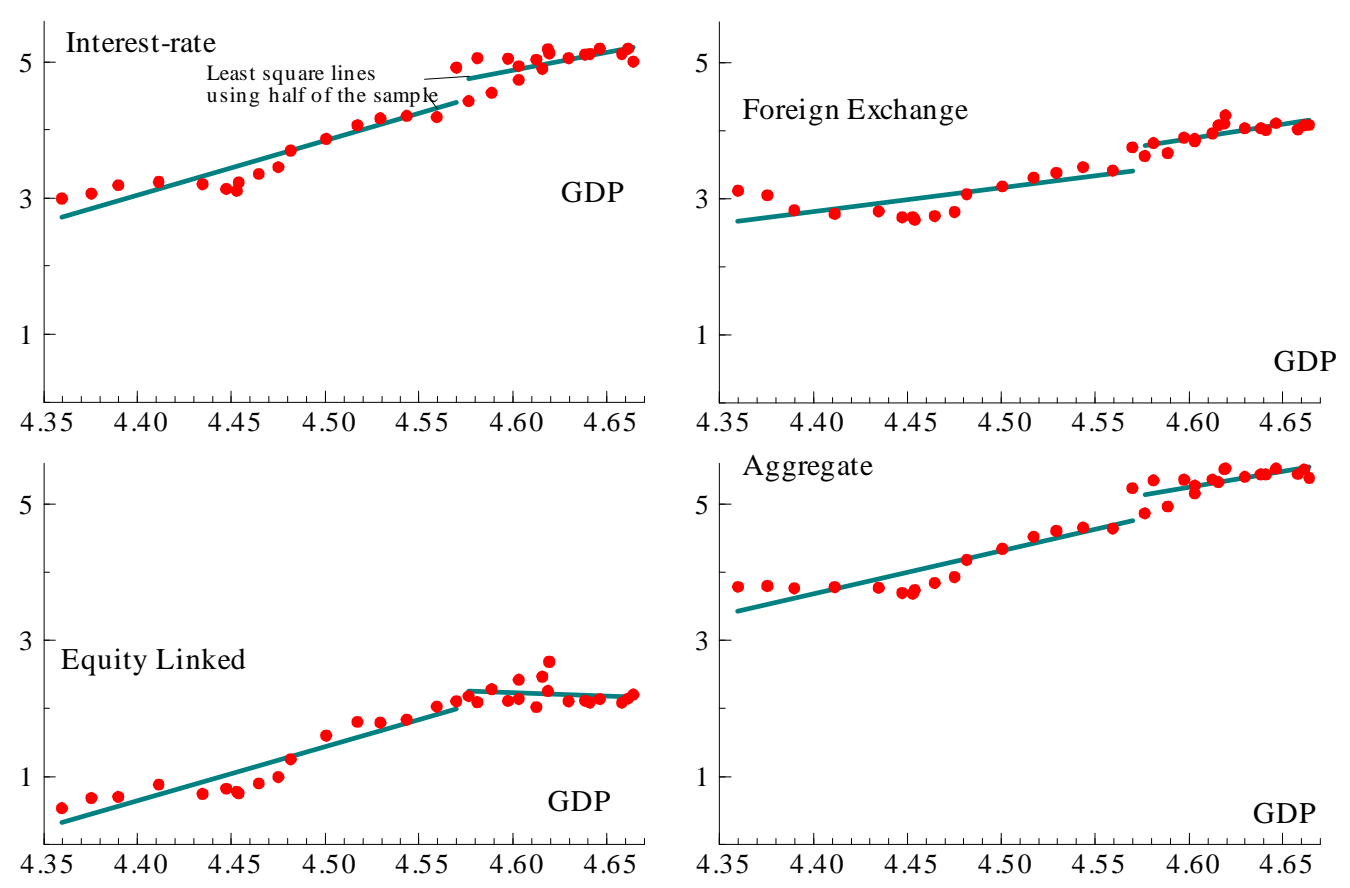

Figure 8. Aggregate Derivatives Across Instruments in real terms and GDP.
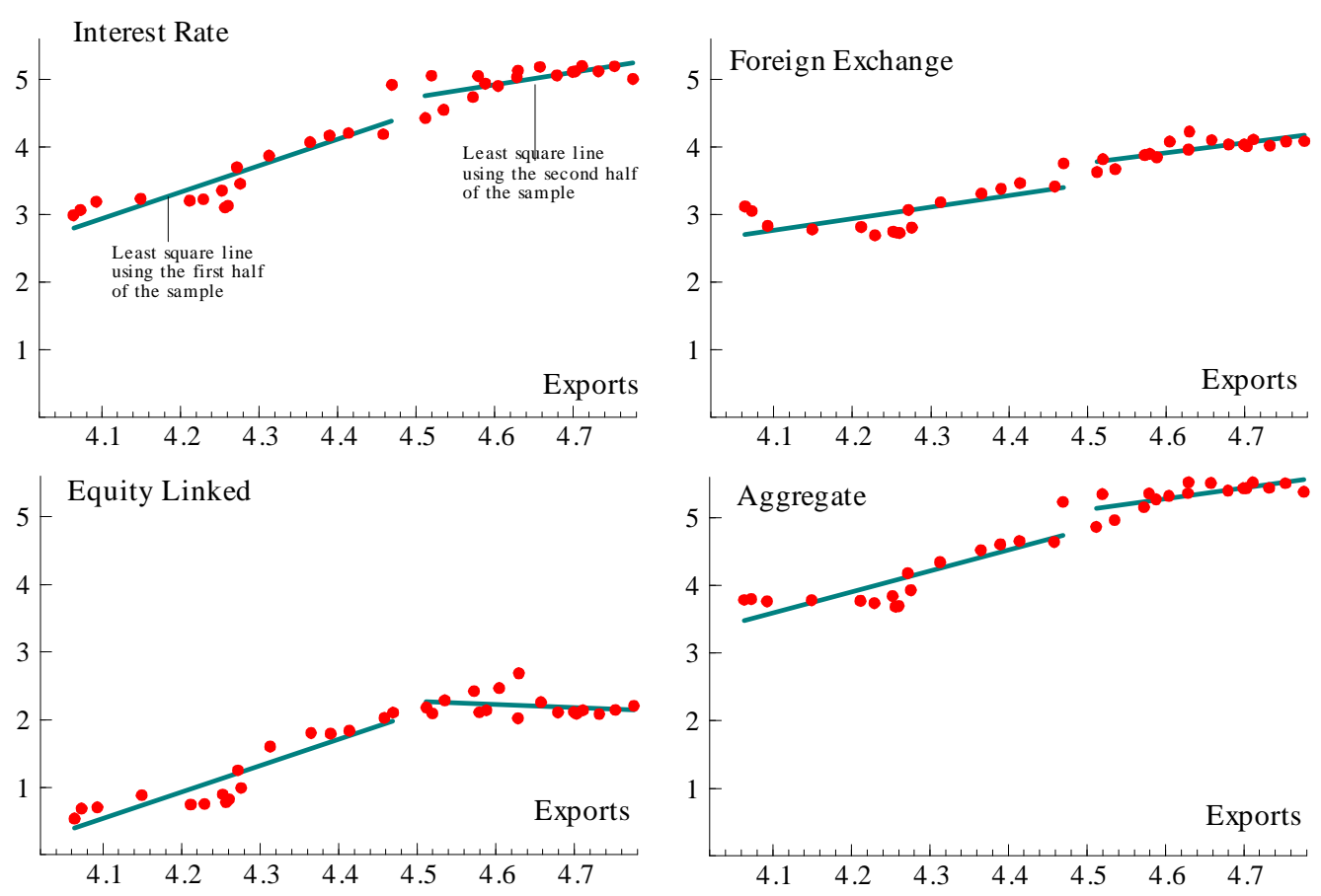

Figure 9. Aggregate Derivatives Across Instruments in real terms and real exports. 

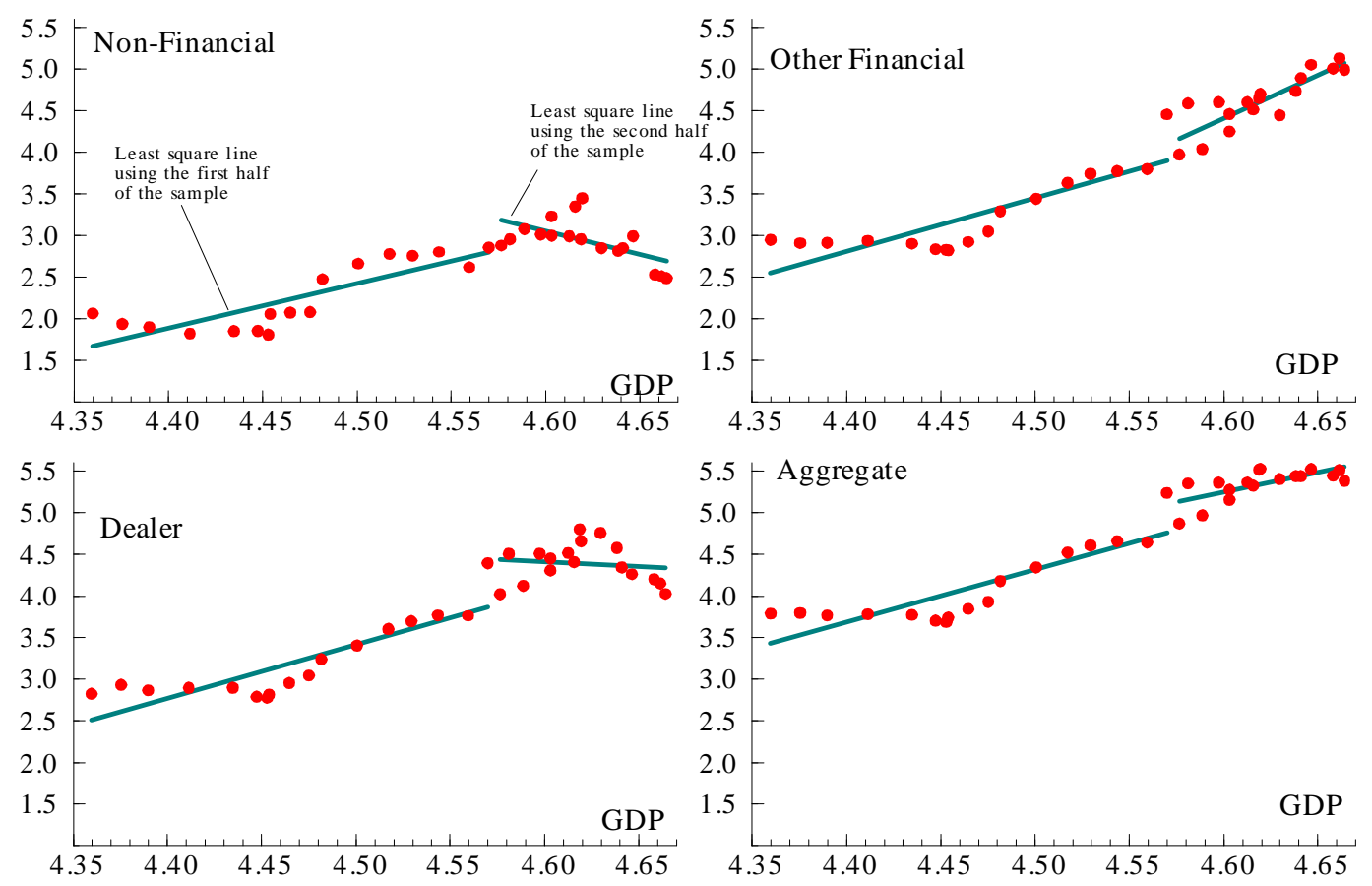

Figure 10. Aggregate Derivatives Across Counterparties in real terms and real GDP.
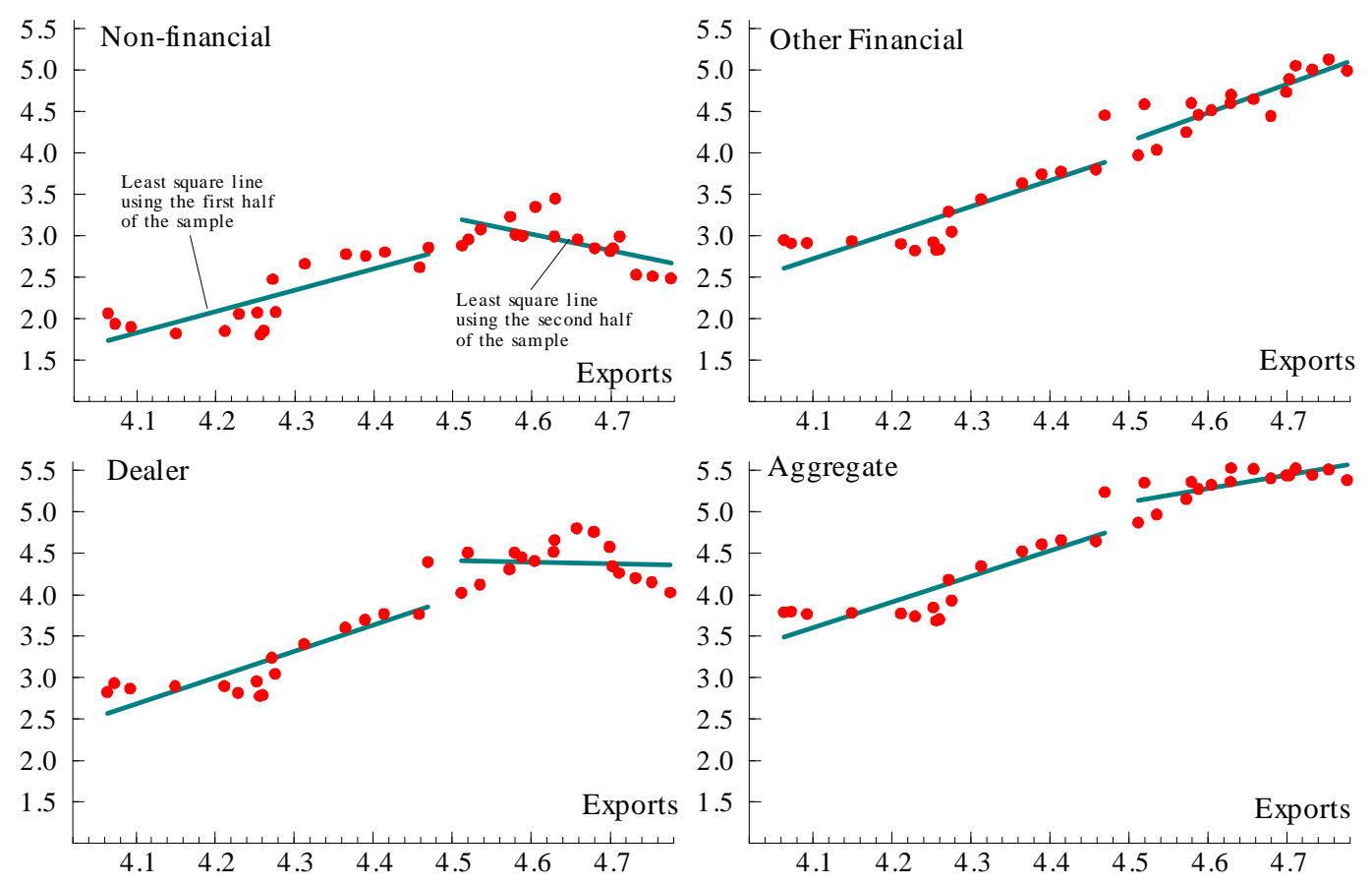

Figure 11. Aggregate Derivatives Across Counterparties in real terms and real exports. 

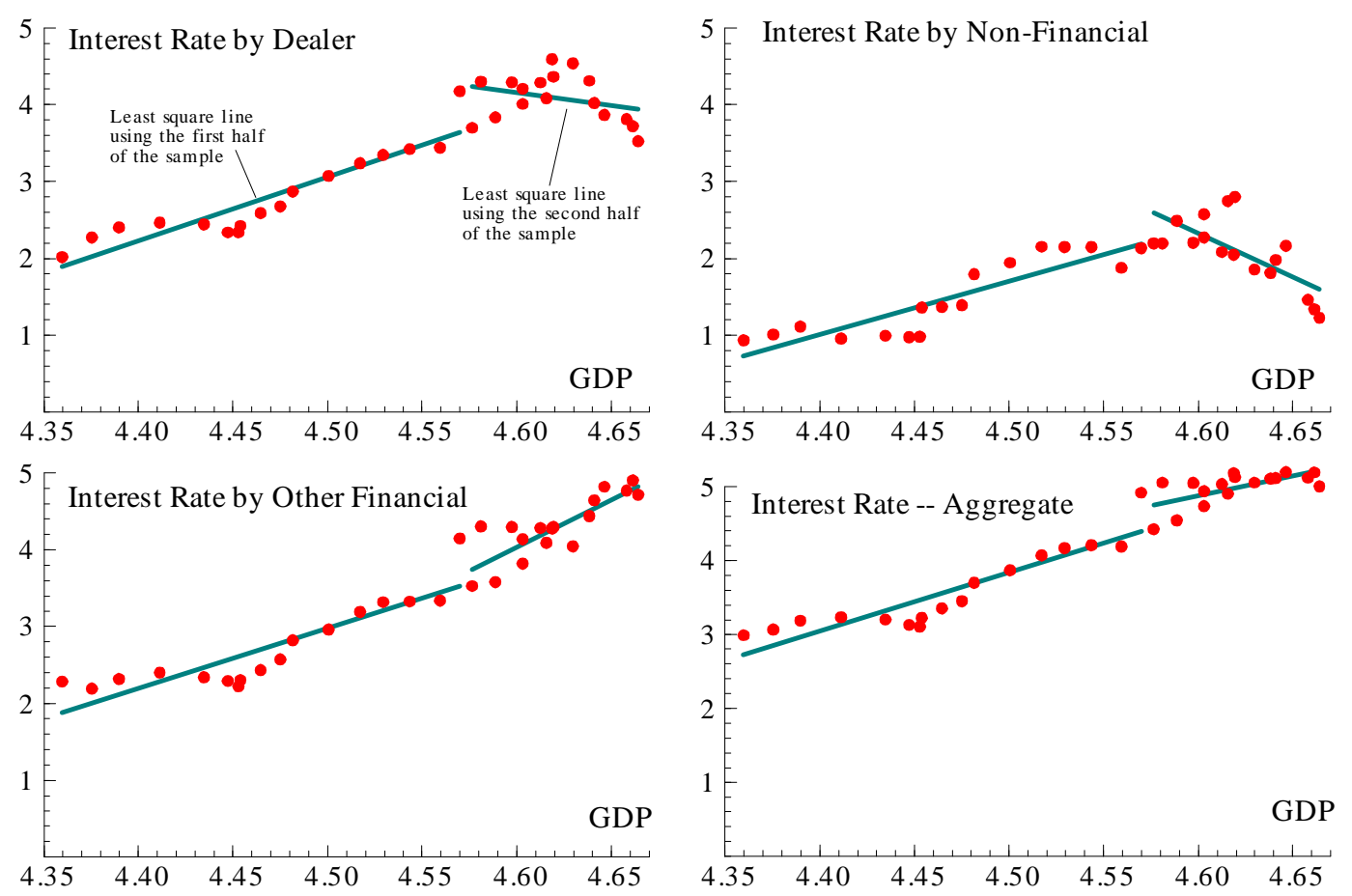

Figure 12. Interest-rate Derivatives by Counterparties in real terms and real GDP.
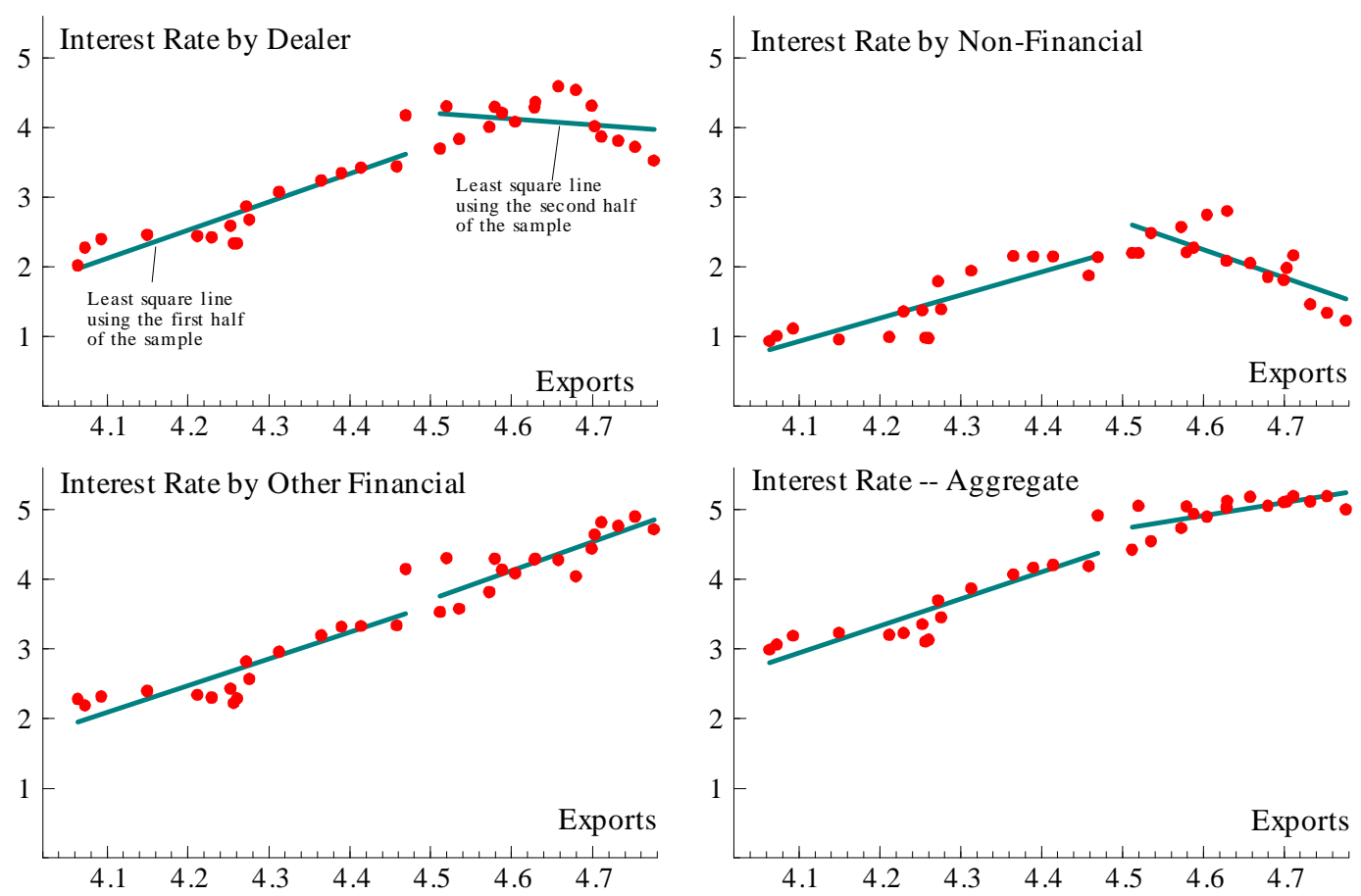

Figure 13. Interest-rate Derivatives by Counterparties in real terms and real exports. 

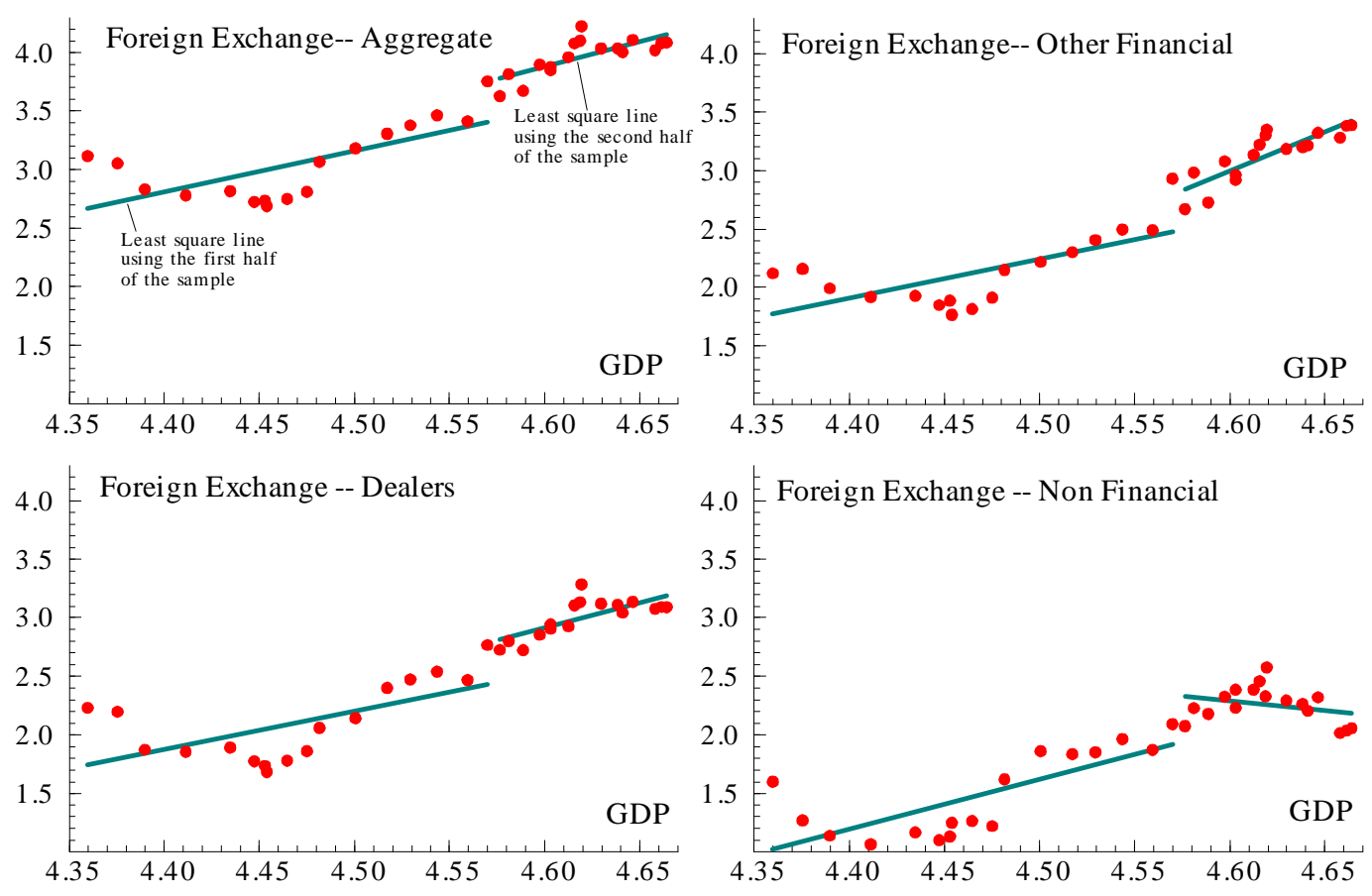

Figure 14. Foreign Exchange Derivatives by Counterparties in real terms and real GDP.
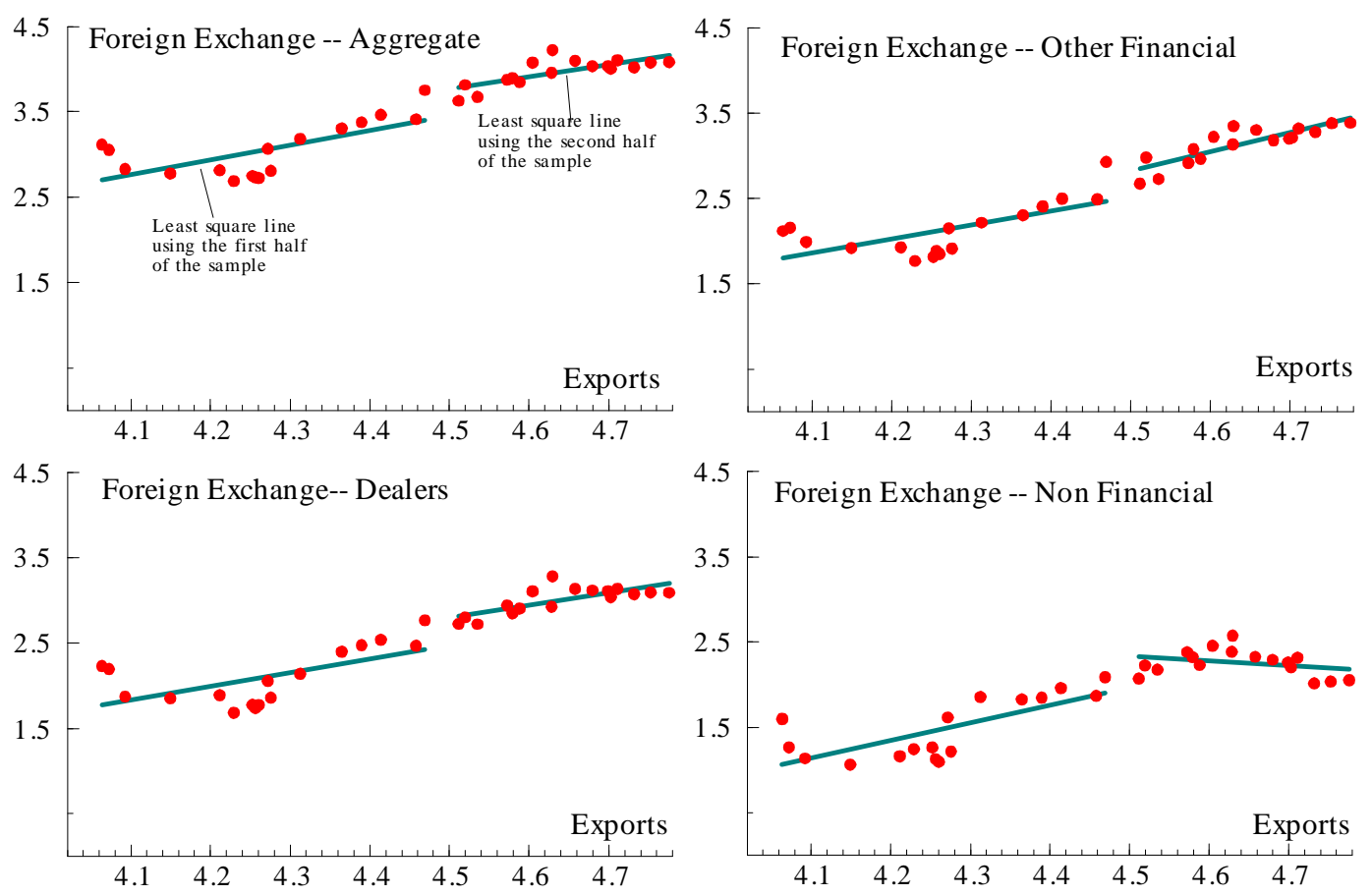

Figure 15. Foreign Exchange Derivatives by Counterparties in real terms and real exports.

The evidence reveals that the unconditional pairwise correlations between OTC derivatives and economic activity are not, in general, reliable: one cannot reliably predict the observations for one half of the sample using the relation from the other half of the sample. The exception to this pattern is OTC contracts for interest-rate derivatives held by Other Financial counterparties; this grouping accounts for 70 percent of all the BIS allocated derivatives (Figure 3). For this grouping, we find that the correlation is robust to both the measure of economic activity and to changes in samples. 
Clearly, there is nothing sacred about splitting the sample in half. The only appeal of our choice is that it is not subject to the criticism that the cutoffs values are chosen after observing the data. However, changes in the slopes of the regression lines might be revealing a non-linearity instead of an instability. We argue that the appearance of nonlinearity is the result of relying on pairwise correlations without controlling for dynamic adjustments and omitted factors. The cointegration analysis that we purse follows this alternative. ${ }^{15}$

\subsection{Econometric Formulation}

Unconditional pairwise correlations, though informative, have limitations for our purposes: They abstract from the role of dynamic adjustments and they exclude the role of third factors. To address these limitations, we postulate a vector-error correction model to explain the growth rates of OTC derivatives, denoted as $d$ (the entries in Table 1 above) and OECD's economic activity, denoted as $a$ (GDP and exports of goods and services) in terms of their own lags, the lagged levels of $d$ and $a$, and a vector of control variables:

$$
\left(\begin{array}{l}
\Delta \ln d_{t} \\
\Delta \ln a_{t}
\end{array}\right)=\left(\begin{array}{ll}
\lambda_{1}(L) & \lambda_{2}(L) \\
\lambda_{3}(L) & \lambda_{4}(L)
\end{array}\right)\left(\begin{array}{c}
\Delta \ln d_{t} \\
\Delta \ln a_{t}
\end{array}\right)+\underbrace{\left(\begin{array}{ll}
\pi_{11} & \pi_{12} \\
\pi_{21} & \pi_{22}
\end{array}\right)}_{\Pi}\left(\begin{array}{l}
\ln d_{t-1} \\
\ln a_{t-1}
\end{array}\right)+\text { controls }+\left(\begin{array}{l}
u_{d t} \\
u_{a t}
\end{array}\right),
$$

where $\left(u_{d t} u_{a t}\right)^{\prime \sim} I N(0, \Omega)$ and $\lambda_{i}(L)$ is a polynomial in the lag operator $L$. By design, Equation (1) avoids both simultaneity biases and spurious correlations, and it decomposes responses to shocks into short-run dynamics and adjustments to long-run.

Specifically, the long-run specification implied by Equation (1) is obtained by setting $\Delta \ln d_{t}=\Delta \ln a_{t}=0$ :

$$
\left(\begin{array}{l}
0 \\
0
\end{array}\right)=\left(\begin{array}{ll}
\lambda_{1}(L) & \lambda_{2}(L) \\
\lambda_{3}(L) & \lambda_{4}(L)
\end{array}\right)\left(\begin{array}{l}
0 \\
0
\end{array}\right)+\underbrace{\left(\begin{array}{ll}
\pi_{11} & \pi_{12} \\
\pi_{21} & \pi_{22}
\end{array}\right)}_{\Pi}\left(\begin{array}{c}
\ln d \\
\ln a
\end{array}\right)
$$

which implies that

$$
\underbrace{\left(\begin{array}{ll}
\pi_{11} & \pi_{12} \\
\pi_{21} & \pi_{22}
\end{array}\right)}_{\Pi}\left(\begin{array}{l}
\ln d \\
\ln a
\end{array}\right)=0 .
$$

For Equation (3) to yield a meaningful long run relation, it must satisfy two conditions. First, both $\ln d$ and $\ln a$ must be integrated of order one. Figure 16 shows the autocorrelation function for the levels for these variables, along with the Augmented Dickey Fuller tests. ${ }^{16}$ The results reveal that these two variables are non stationary. Figure 17 shows the autocorrelation function for the differences of the same two variables and the results indicate that that their differences are stationary. These findings suggest that one cannot reject the view that $\ln d$ and $\ln a$ are integrated of order one:

15 Thanks to one of the referees for calling this point to our attention.

16 The test result that we report is the one that minimizes the Akaike's Information Criteria. The critical values for the ADF test are $5 \%-1.95 ; 1 \%-2.65$. 

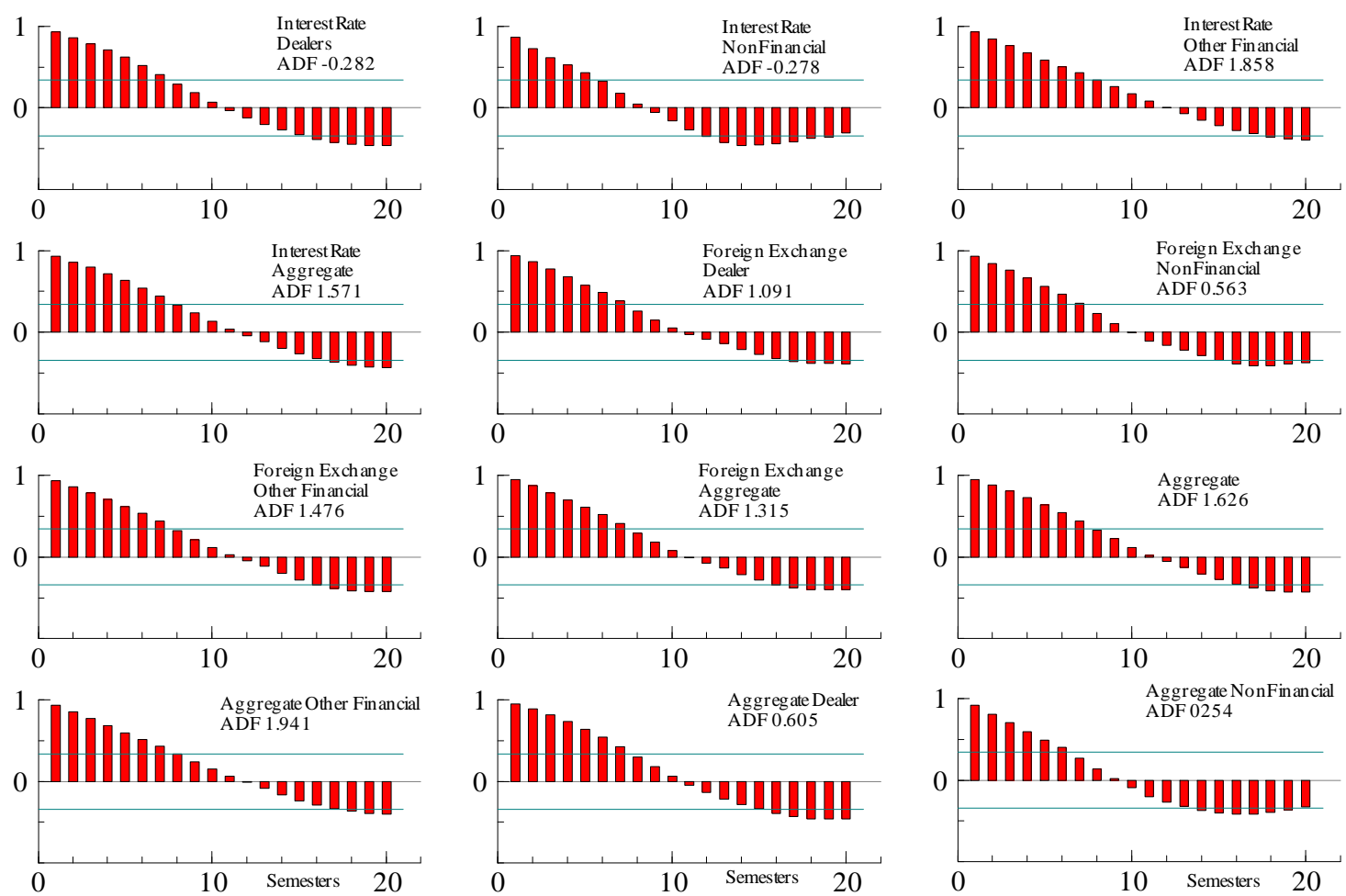

Figure 16. Autocorrelation function for OTC derivatives by counterparty and instrument. The horizontal green lines are the critical values for the hypothesis that the autocorrelation is zero.
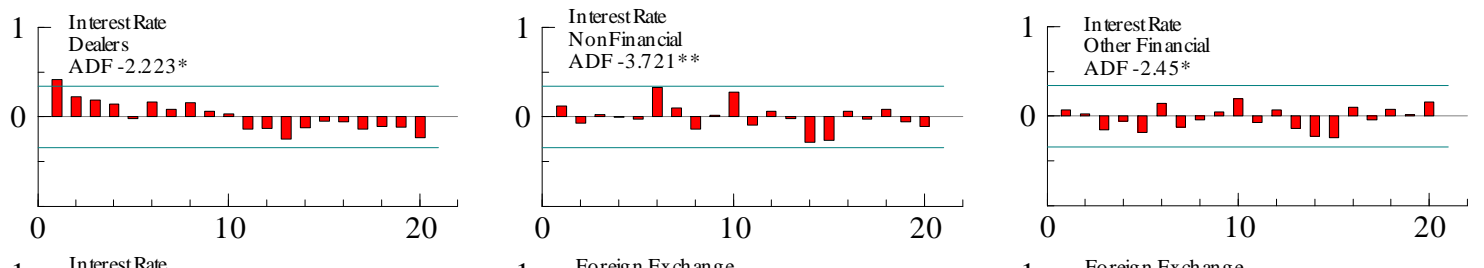

1 In terest Rate

Aggregate
$\mathrm{ADF}-2.075^{*}$
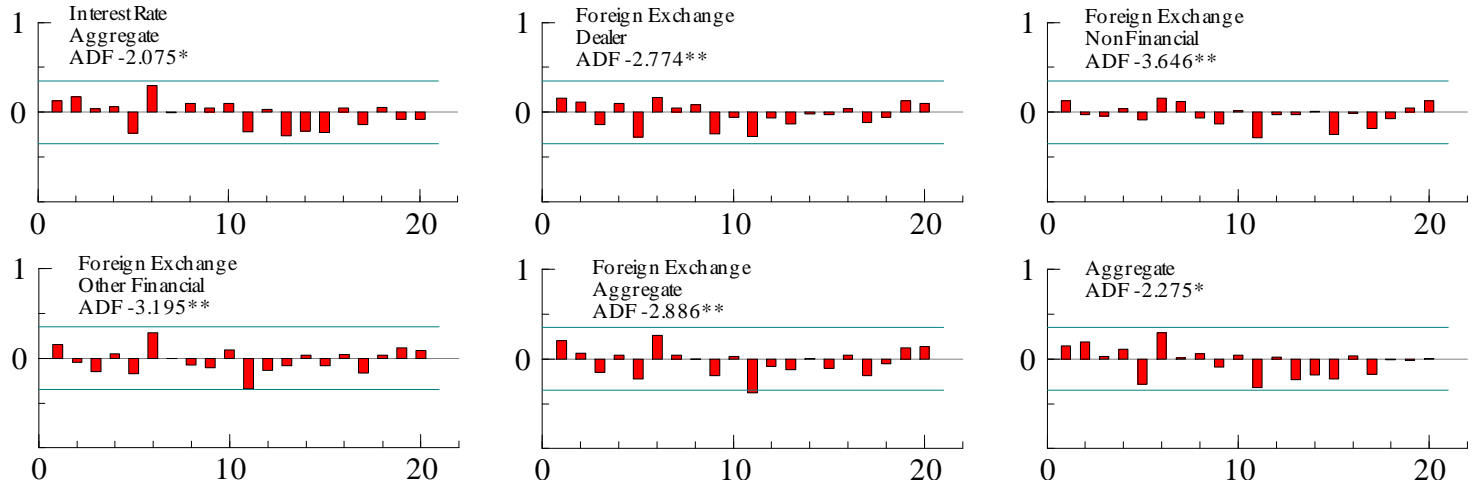

1 Aggregate
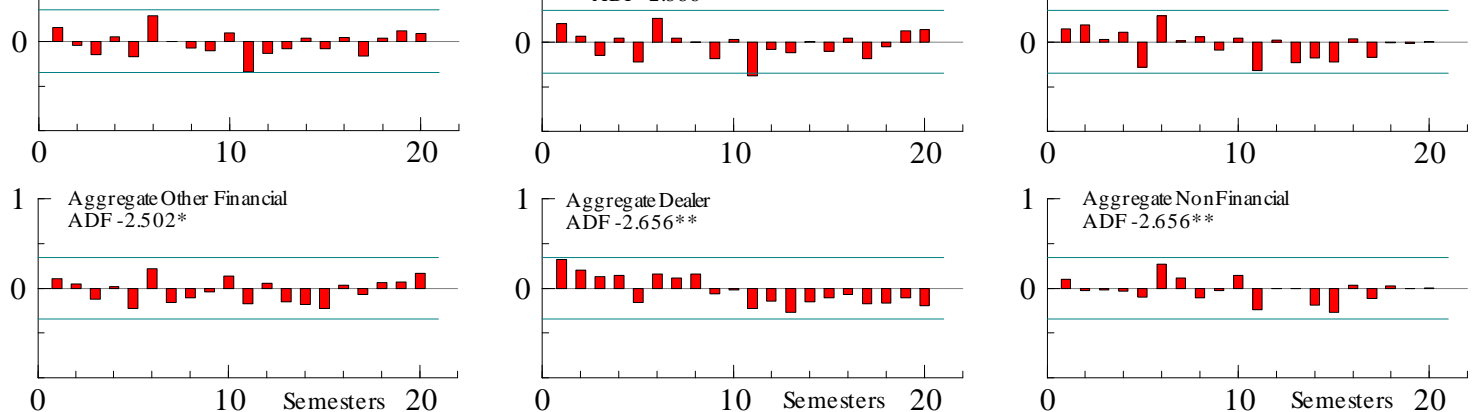

Figure 17. Autocorrelation Function forthe growth rates of OTC derivatives by counterparty and instrument. The horizontal green lines are the critical values for the hypothesis that the autocorrelation is zero. 
The second condition is for $\Pi$ to have a rank of 1 . In that case, $\Pi$ can be decomposed as

$$
\Pi=\left(\begin{array}{c}
\alpha_{d} \\
\alpha_{a}
\end{array}\right) \cdot\left(\begin{array}{ll}
1 & -\beta
\end{array}\right)=\left(\begin{array}{cc}
\alpha_{d} & -\alpha_{d} \cdot \beta \\
\alpha_{a} & -\alpha_{a} \cdot \beta
\end{array}\right)
$$

where $\beta$ is the "cointegration" coefficient between $d$ and $a$; and $\alpha_{d}$ and $\alpha_{a}$ are the "loading" coefficients. Substituting Equation (4) into (2) yields

$$
\left(\begin{array}{c}
\Delta \ln d_{t} \\
\Delta \ln a_{t}
\end{array}\right)=\underbrace{\left(\begin{array}{cc}
\lambda_{1}(L) & \lambda_{2}(L) \\
\lambda_{3}(L) & \lambda_{4}(L)
\end{array}\right)\left(\begin{array}{c}
\Delta \ln d_{t} \\
\Delta \ln a_{t}
\end{array}\right)}_{\text {short-run responses }}+\underbrace{\left(\begin{array}{c}
\alpha_{d}(\ln d-\beta \cdot \ln a)_{t-1} \\
\alpha_{a}(\ln d-\beta \cdot \ln a)_{t-1}
\end{array}\right)}_{\text {adjustment to long-run }}+\text { controls }+\left(\begin{array}{c}
u_{d t} \\
u_{y t}
\end{array}\right)
$$

Thus, assuming that $\alpha_{d} \neq 0$ and $\alpha_{a} \neq 0$, the long-run relation is

$$
\ln d_{t}=\beta \cdot \ln a_{t} .
$$

Equation (6) makes clear why the variables need to be integrated of order one. If they were not, the estimate of $\beta$ would be zero. Further, Equation (6) is not the equation explaining derivatives. Indeed, both $a$ and $d$ are endogenous variables and their evolution is determined by Equation (5) as implemented in Sections 3.4.6 and 4.1 below. Finally, combining Equation (5) and (6) embody the dynamics of the adjustment to the long-run relation.

Specifically, if $\ln d_{t-1}-\beta \cdot \ln a_{t-1}>0$, then derivatives are above their long-run value and so we expect a reduction in the growth rate of derivatives and an increase in the growth rate of economic activity. Whether this expectation is supported by the data depends on whether $\alpha_{d}<0$ and $\alpha_{a}>0$. If these conditions are met, then departures from the long-run (Equation (6)) are transitory.

An alternative to Equation (5) is the Engle-Granger method. Their method asserts that the long-run relation is

$$
\ln d_{t}=c+\beta \cdot \ln a_{t}+\text { controls }+\varepsilon_{t}, \varepsilon_{t} \tau I N(0, \sigma),
$$

applies OLS to estimate $\beta$, and then tests whether the estimated residuals $\varepsilon_{t}$ are stationary. Their approach is appealing because of its transparency and ease of implementation. On the other hand, their approach forces the researcher to treat one of the two variables as exogenous, which limits the usefulness of the results.

For controls we use OECD real government purchases to control for aggregate demand shocks; the real price of oil to control for supply shocks; the S\&P500 VIX to control overall uncertainty; and a dummy equal to one in 2008-H2 for the collapse of Lehman Brothers. We also considered as additional controls the growth rate of the real money supply and the CPI inflation rate. We do not use them because they have little explanatory power and use precious degrees of freedom.

\subsection{Cointegration Tests}

\subsubsection{Implementation}

For estimation we consider the following configurations:

- 2 measures of economic activity (a): Real GDP and Real Exports of goods and services

- 3 counterparties and their aggregate: Non-Financial, Other Financial, Dealers, and Aggregate

- 2 instruments: Foreign-Exchange derivatives and Interest-Rate derivatives ${ }^{17}$

17 Contracts on equity-linked derivatives are negligible and they are excluded from the modeling work. Their values are, however, included in the computation of the aggregates for the various counterparties; Section 3.1 shows the data matrix that we use. 
- $\quad$ lags varying from 3 to 8 semesters.

For each configuration we examine whether the associated results are consistent with white noise residuals, parameter constancy, dynamic stability. If these conditions are met, then we apply Johansen's cointegration tests: the Trace and Max tests (adjusted by degrees of freedom) ${ }^{18}$ At this point, we re-test whether the residuals are white noise and whether the cointegration vector is constant over time.

\subsubsection{Results}

The only category meeting these criteria is OTC contracts for interest-rate derivatives held by Other Financial counterparties. Table 2 shows the estimation results:

Table 2. Estimated Long Run Coefficients: 2002-2014-Alternative Estimation Methods.

\begin{tabular}{|c|c|c|c|c|c|}
\hline \multirow{2}{*}{ Economic Activity (a) } & \multicolumn{4}{|c|}{ Johansen } & \multirow[t]{2}{*}{ Engle-Granger $* 19$} \\
\hline & & $\beta$ & $\alpha_{d}$ & $\alpha_{y}$ & \\
\hline \multirow{2}{*}{ GDP } & $(s e)$ & $\begin{array}{c}4.98 \\
(1.27)\end{array}$ & $\begin{array}{l}-1.15 \\
(0.24)\end{array}$ & $\begin{array}{c}0.0095 \\
(0.0176)\end{array}$ & $\begin{array}{c}4.45 \\
(1.34)\end{array}$ \\
\hline & $(s e)$ & $\begin{array}{c}4.696 \\
(1.269)\end{array}$ & $\begin{array}{c}-1.12 \\
(0.229)\end{array}$ & $-t$ & \\
\hline \multirow{2}{*}{ Exports } & $(s e)$ & $\begin{array}{c}1.887 \\
(0.304)\end{array}$ & $\begin{array}{c}-1.156 \\
(0.24)\end{array}$ & $\begin{array}{l}0.0689 \\
(0.076)\end{array}$ & $\begin{array}{c}1.23 \\
(0.598)\end{array}$ \\
\hline & $(s e)$ & $\begin{array}{l}1.8276 \\
(0.304)\end{array}$ & $\begin{array}{c}-1.5347 \\
(0.241)\end{array}$ & -+ & \\
\hline
\end{tabular}

${ }^{*}$ Robust Standard Errors; + Exclusion based on the log-likelihood ratio test (not shown).

The estimate of $\beta$ is positive, significant, and robust to estimation method. The estimate of $\alpha_{d}$ is negative and the estimate of $\alpha_{a}$ is positive, which suggest that deviations from a long-run are temporary. The estimates of $\beta$ are, however, sensitive to the measure of economic activity: the estimate of $\beta$ using GDP is much larger than the corresponding estimate using exports. To address which measure is the relevant one, we now focus on the statistical reliability of the two formulations.

\subsubsection{Statistical Reliability}

We examine the fit of the model, test whether the residuals are white noise residuals, assess whether the model is dynamic stable, and test whether $\beta$ exhibits constancy; details of these tests are available Doornik and Hendry (2013).

\subsubsection{Model Fit}

The models' fit of the data are shown in Figures 18 and 19:

These results suggest that both models offer a good predictive power of the data and there are no residuals exceeding twice their standard error. Overall, model fit alone does not allows to discriminate between the two models.

18 See Doornik and Hendry (2013) for the empirical implementation of this test.

19 We could not reject the view that the residuals from the Engle-Granger equation are stationary. 

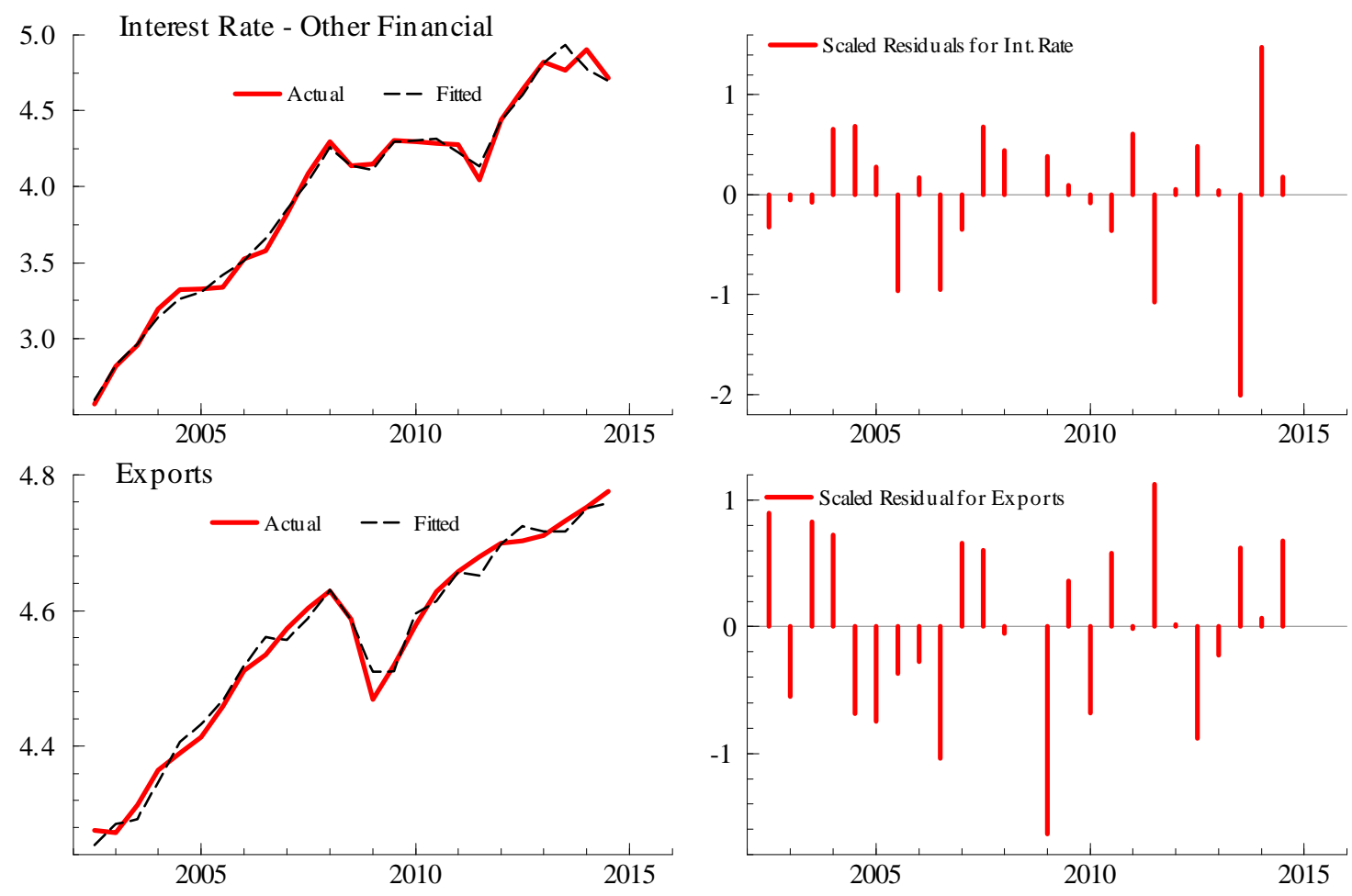

Figure 18. Fit versus Actual (Left Panels) and Scaled Residuals (Right Panels) using real exports.
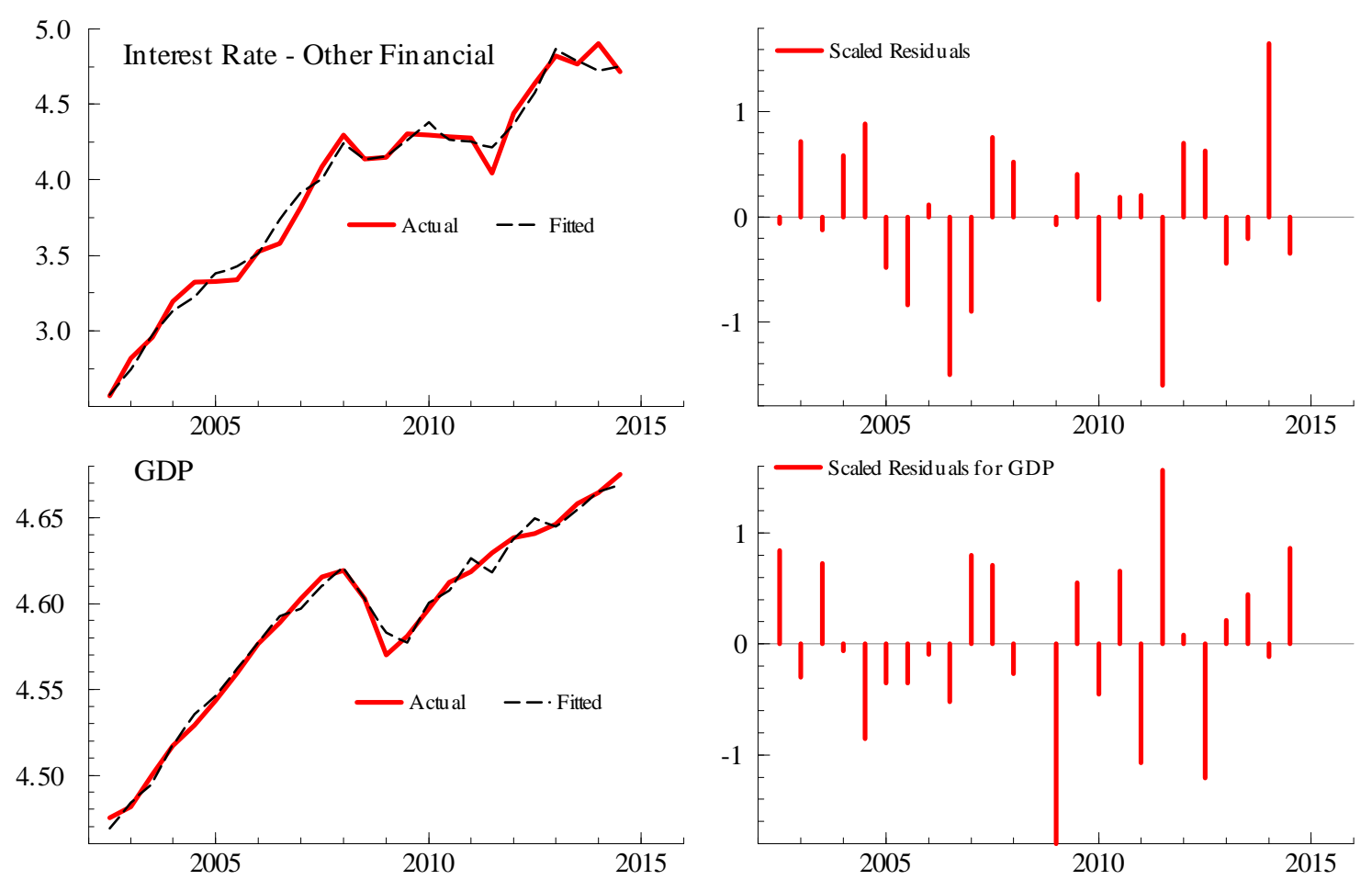

Figure 19. Fit versus Actual (Left Panels) and Scaled Residuals (Right Panels) using real GDP. 


\subsubsection{Residuals' Properties}

To test whether the residuals are consistent with being white noise, we use the empirical distributions of the residuals and then test for normality, serial independence, and homoskedasticity. ${ }^{19}$ Table 3 reports the significance levels needed to reject each of these hypotheses:

Table 3. Critical Values for Rejecting Residuals' Properties.

\begin{tabular}{lccc}
\hline \multirow{2}{*}{ Model } & \multicolumn{3}{c}{ Null Hypothesis } \\
\cline { 2 - 4 } & Normality & Serial Ind. & Homosk. \\
\hline Interest Rates & 0.639 & 0.074 & 0.475 \\
and GDP & 0.816 & 0.084 & 0.274 \\
Interest Rates & 0.077 & 0.172 & 0.309 \\
and Exports & 0.639 & 0.074 & 0.475 \\
\hline
\end{tabular}

The results indicate that one cannot reject the hypothesis that the residuals are white noise and this result is robust to the measure of economic activity.

\subsubsection{Dynamic Stability}

To examine whether the model is dynamically stable, we apply one-time (unit) shocks to the residuals. Using exports as measure of economic activity, we find unstable responses that do not dissipate after 12 years (Figure 20). Thus we do not consider further the role of exports for explaining derivatives.

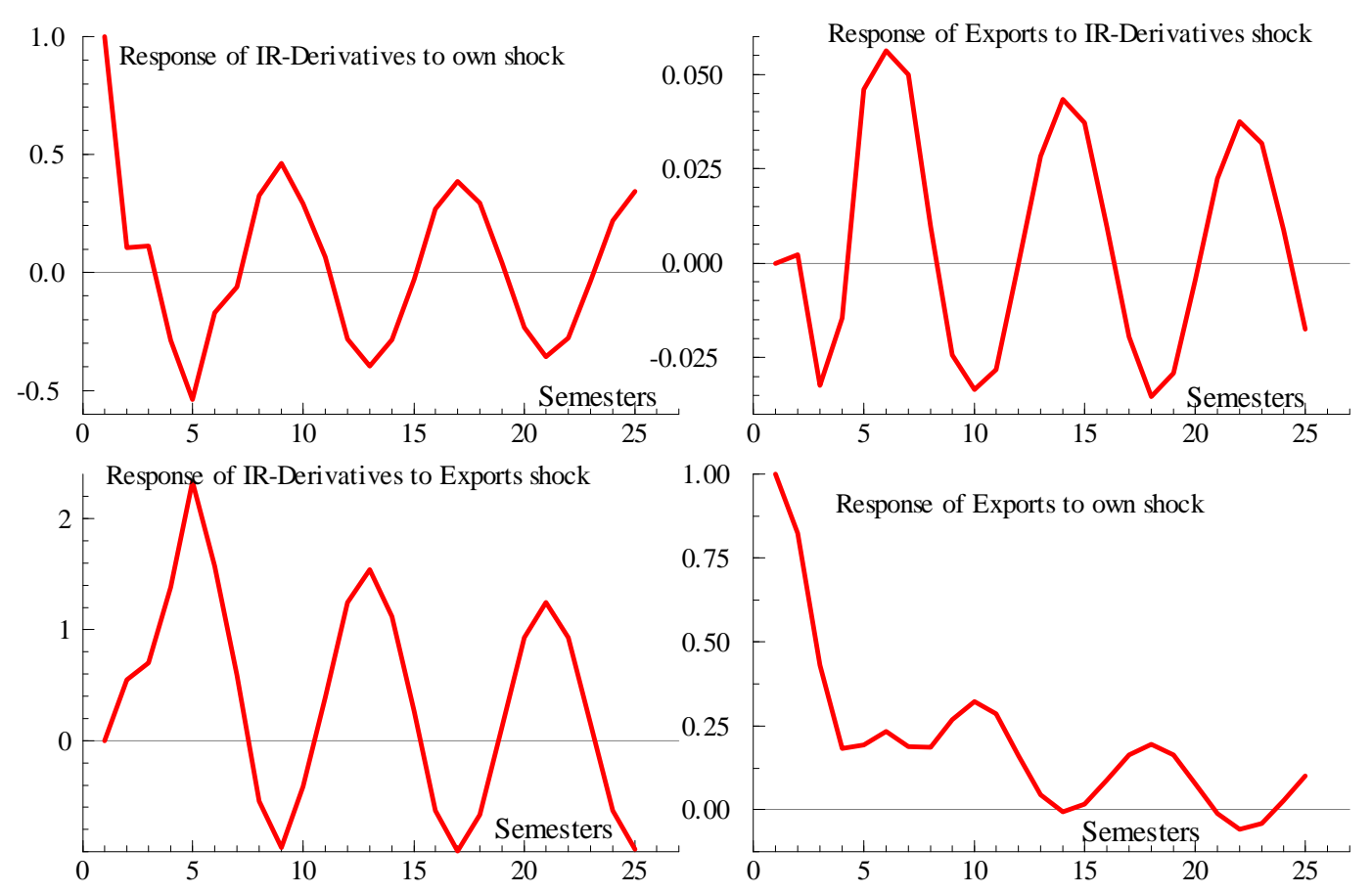

Figure 20. Impulse responses with economic activity measured with exports.

Using GDP as measure of economic activity, we also find oscillating responses but they decline after five years (Figure 21):

19 For normality we use the Jarque-Bera test. For serial independence we test the hypothesis that all of the coefficients of an $\mathrm{AR}(7)$ of the residuals are jointly equal to zero. For homoskedasticity we test whether the residuals exhibit an ARCH of order 1. These tests are explained in Doornik and Hendry (2013). 

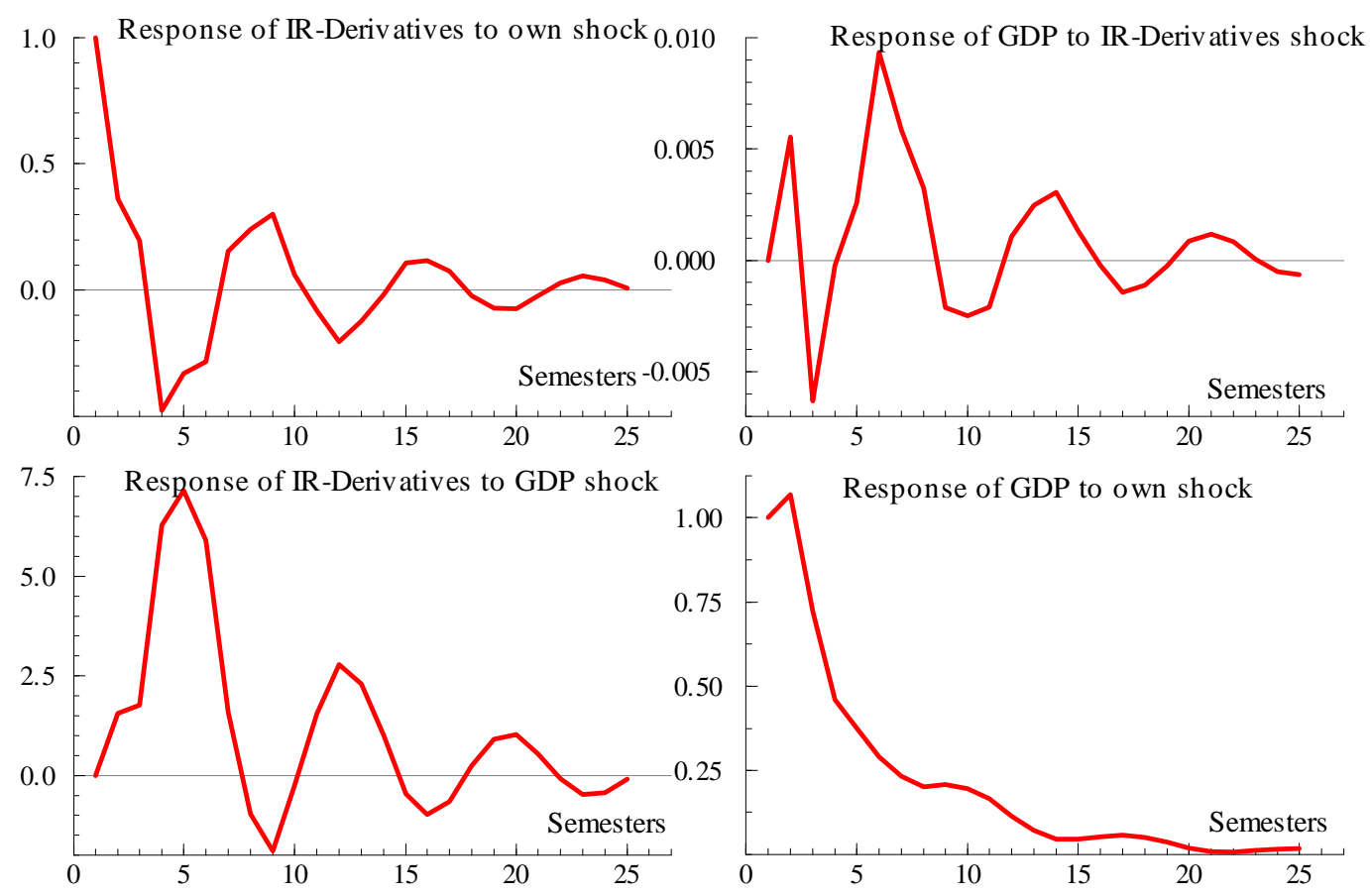

Figure 21. Impulse responses with economic activity measured with GDP.

Note that the initial response of interest-rate derivatives to a unit shock in GDP is more than proportional and then dies down quickly. In contrast, the response of GDP to a unit shock in interest-rate derivatives is negligible; this result confirms the findings from BIS (2013).

\subsubsection{Parameter Constancy}

To examine whether the estimate of $\beta$ is constant, we estimate it recursively. We begin with a sample of ten observations and then proceed to increase the sample size one observation at a time. Figure 22 shows the fan chart for the recursive estimates of $\beta$ :

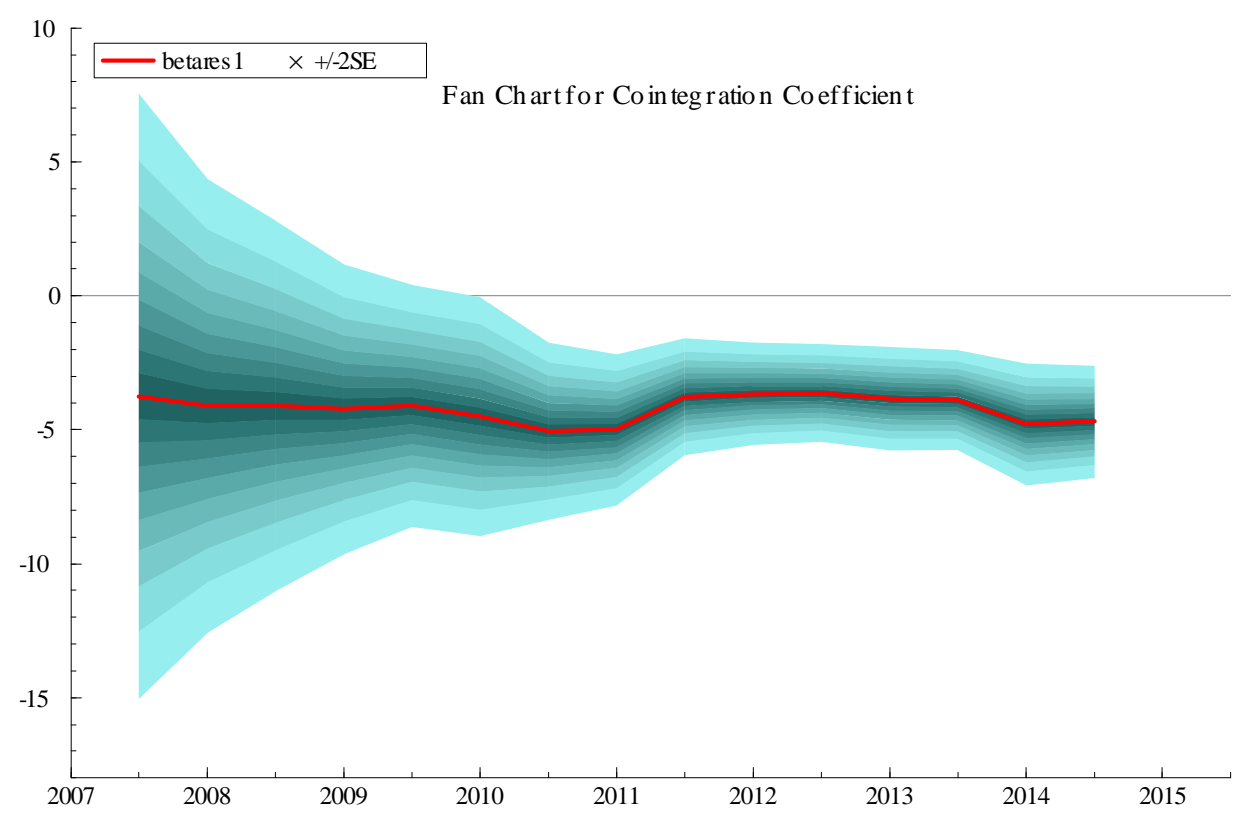

Figure 22. Recursive 95\% Confidence Band for Cointegration Coefficient. 
The estimation results reveal that $\beta$ can be treated as constant. Note that the width of the confidence band is initially large initially because we initialize the recursive estimation with 10 observations.

\section{Applications}

The evidence assembled so far reveals a statistically reliable characterization of the interdependency between GDP and interest-rate derivatives of other financial institutions. We now use this model to study two practical questions: the macroeconomic effects of hypothetical regulations of the OTC market for derivatives and the contribution of speculative trading in that market.

\subsection{Estimating the Effects of Regulations}

Current regulatory efforts of the OTC derivatives market neglect the potential macroeconomic effects of those regulations and offer no evidence justifying this neglect. ${ }^{20}$ Though a complete answer to the question of the macro effects of regulations on OTC derivatives is beyond the scope of this paper, our framework might help providing a preliminary answer this question. To that end, we simulate the effects of a one-time contraction of $10 \%$ in the level of real interest-rate derivatives held by Other Financial counterparties on GDP. Figure 23 shows the associated responses:
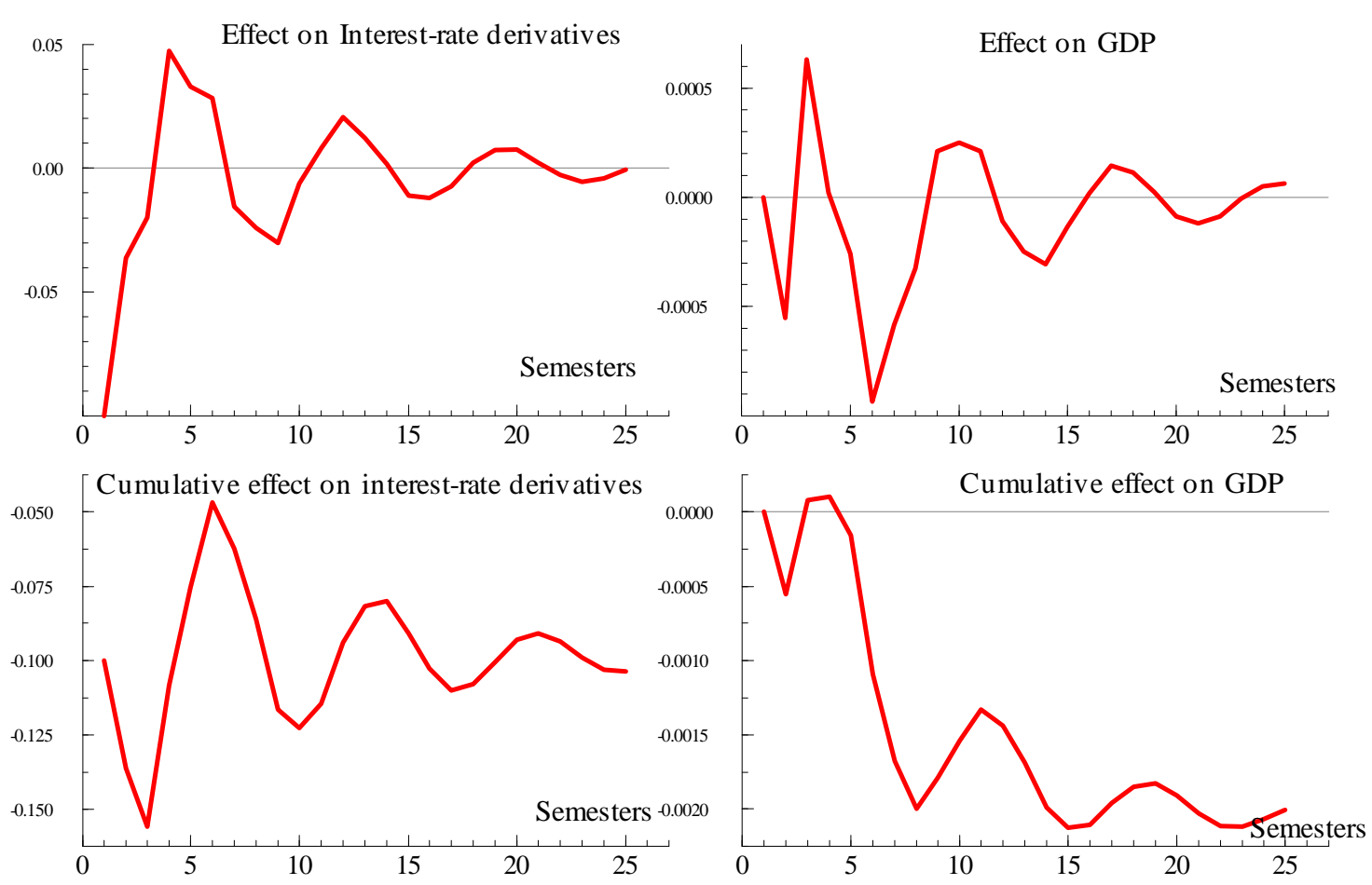

Figure 23. Response to a hypothetical 10\% contraction in OTC Derivatives.

The results show a contraction in the level of real GDP of 0.2 percent after 12 years, which is small relative to the GDP contraction during the great recession (see Figure 7 above). These findings, however, abstract from important institutional differences in regulatory bodies across countries and presume a degree of cooperation among these bodies that is rare in practice. Notwithstanding these limitations, our findings are aligned with those of the BIS' Macroeconomic Assessment Group on

20 Dudley (2013) and Lew (2013) discuss the extent and manner in which the OTC market for derivatives might be regulated. Greenspan (1998) and Summers (1998) argue strongly against regulation. 
Derivatives which also finds that regulations on derivatives will have a minimal effect on economic activity (BIS 2013, p. 14). ${ }^{21}$

\subsection{Estimating Speculative Trades}

In summarizing the results of a May 2017 Federal Reserve Bank of New York's conference on the regulation of OTC derivatives, Boyarchenko et al. (2017) note that

...In the run-up to the financial crisis, OTC derivatives markets grew rapidly, with interest rate and credit derivatives growing the fastest, as shown in the chart below. While these derivatives provide an important vehicle for hedging economic risks, recent academic literature has argued that market participants also use these markets to take speculative directional exposures....

As evidence of their views, they report the evolution of the BIS data for the Global OTC derivatives from 2005 to 2008. Their conclusion, however, is subject to an identification problem: How do they know that this rise in these derivatives was speculative as opposed to related to the expansion in economic activity that was also taking place at the time?

To address the identification problem, we interpret speculative behavior as inducing OTC trading above from what one would expect based on the long-run relation between GDP and OTC derivatives (Equation (6) above). Specifically, finding that OTC trading exceeds its long run value would be consistent with speculative activity-namely, unrelated to GDP. Figure 24 shows deviations from the long run computed as $[\ln d-4.7 \ln y]$ :

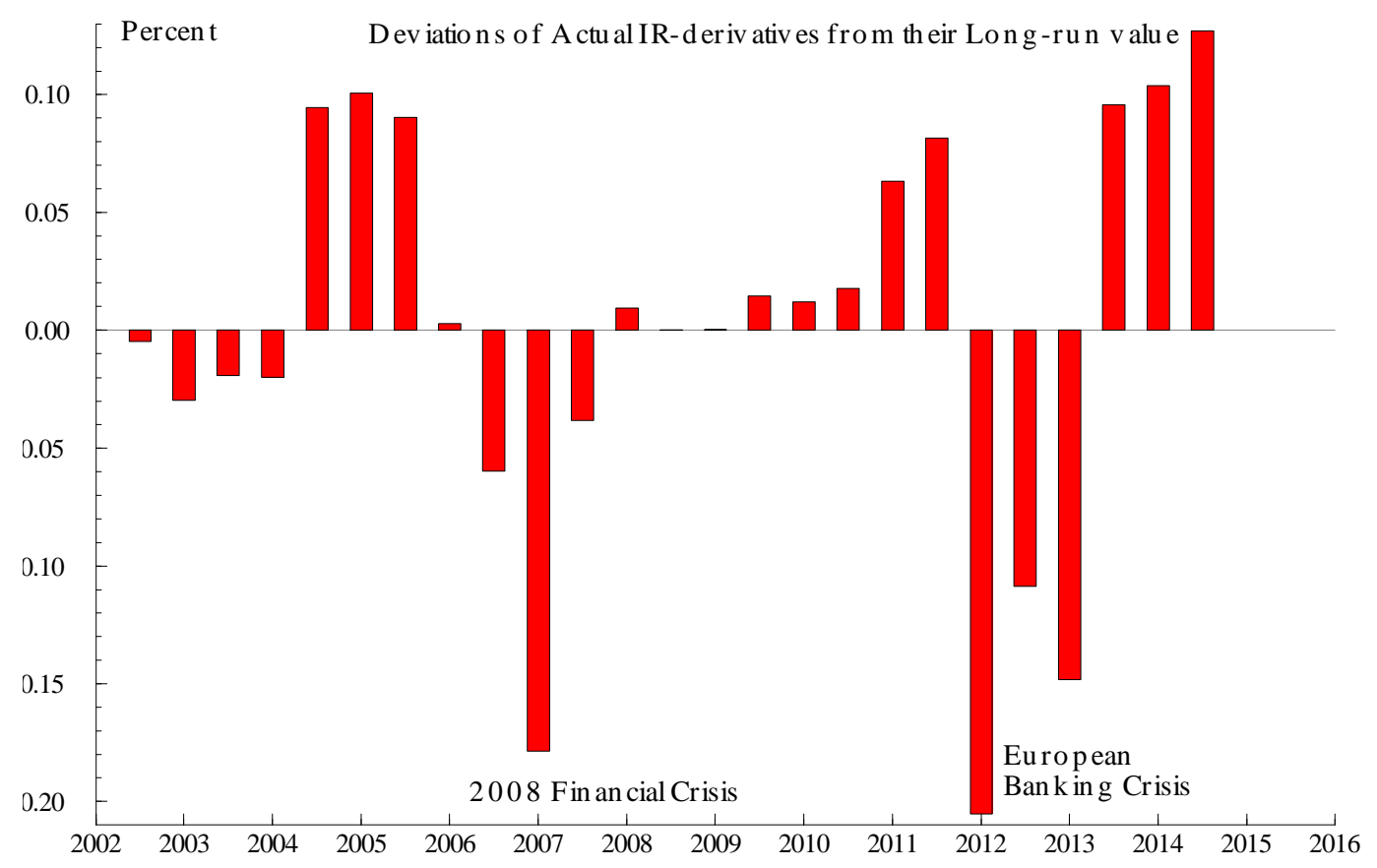

Figure 24. Deviations of Derivatives from their long run value as predicted by the cointegration relation.

The results reveal that interest-rate derivatives held by Other Financial institutions exceeded their long run value during the housing expansion that took place both in Europe and the United States and

21 However, the BIS calculations do not recognize the feedback effect from GDP to derivatives. BIS (2013) empirical work relies on models that treat the effect of income on derivatives as given. The idea is that deriviatives affect the cost of capital and therefore investment and therefore GDP. Our contribution lies on treating economic activity as responding to regulations of derivatives. 
below their long run value during the U.S. financial crisis and the European banking crisis. Again, if one interprets positive deviations as speculative behavior, then these results corroborate the views of Boyarchenko et al. (2017). Our contribution is the quantification of the speculative component: $10 \%$ above what one should expect based on a long-run relation.

\section{Conclusions}

We offer the first empirical characterization of the association between global OTC derivatives and economic activity. To that end, we use BIS data on OTC contracts disaggregated by instrument and by counterparty. Our empirical analysis applies a vector-error correction model to OTC derivatives disaggregated by Instrument and Counterparty. The results indicate that with one exception, the heterogeneity of OTC contracts is too pronounced to be reliably summarized with our model. The one exception is interest-rate derivatives held by Other Financial Institutions (70\% of all the BIS allocated derivatives). For this category, the results indicate that a long-run relation to OECD's GDP, that movements in GDP drive movements in interest-rate derivatives and not the other way around, that a one-time $10 \%$ contraction in OTC derivatives induces a contraction in GDP that after 10 years reaches $0.2 \%$ of GDP.

Our work has several limitations. First, the number of observations is not large. Second, economic activity might be measured with other indicators such as private fixed investment. In other words, tons of work ahead. Until then, the findings have an undeniable tentative character.

Acknowledgments: We are very grateful to two anonymous referees for their extensive and insightful comments. An earlier version of this paper was presented as the 2014 Max M. Fisher Lecture at the Johns Hopkins University School of Advanced International Studies. We are grateful to Andrew Rys for his assistance. We also received very valuable comments from Neil Ericsson, Roger Leeds, and Mark White. We are also grateful to Denis Pêtre from the BIS for comments on the data. The calculations are carried out with OxMetrics; see Doornik and Hendry (2013). We have not received funding from any source to conduct this project.

Author Contributions: Bodnar suggested the idea of examining the interdependency between OTC Derivatives and Economic Activity; he also oversaw the suitability of the OTC data from the BIS and provided . Fortun carried out the programs to generate the coefficient estimates described in Section 3.4.1. Marquez collected the data, designed the estimation framework, and wrote the paper.

Conflicts of Interest: The authors declare no conflict of interest.

\section{References}

Bank for International Settlements. 2013. Macroeconomic Impact Assessment of OTC Derivatives Regulatory Reforms. Available online: http:/ / www.bis.org/publ/othp20.htm (accessed on 12 June 2017).

Bodnar, Gordon M., John Graham, Campbell R. Harvey, and Richard C. Marston. 2011. Managing Risk Management. Available online: http:/ / papers.ssrn.com/sol3/papers.cfm?abstract_id=1787144 (accessed on 12 June 2017).

Boyarchenko, Nina, Or Shachar, and Jacqueline Yen. 2017. At the N. Y. Fed: The Evolution of OTC Derivatives Markets. Available online: http://libertystreeteconomics.newyorkfed.org/2017/05/at-the-ny-fed-theevolution-of-otc-derivatives-markets.html (accessed on 12 June 2017).

Doornik, Jurgen A., and David F. Hendry. 2013. Empirical Econometric Modeling. Vols. I and II. London: Timberlake Consultants.

Dudley, William C. 2013. Remarks at the 2013 OTC Derivatives Conference, Paris, France. Available online: https:/ / www.newyorkfed.org/newsevents/speeches/2013/dud130912.html (accessed on 12 June 2017).

Greenspan, Alan. 1998. Testimony of Chairman Alan Greenspan to The Commodity Exchange Act and OTC derivatives Before the Committee on Agriculture, Nutrition, and Forestry, U.S. Senate July 30, 1998. Available online: http:/ / www.federalreserve.gov/boarddocs/testimony/1998/19980730.htm (accessed on 12 June 2017).

Hopper, Gregory. 1995. A Primer on Currency Derivatives. Available online: https://www.philadelphiafed.org/ research-and-data/publications/business-review/1995 (accessed on 12 June 2017).

Lew, Jacob J. 2013. Testimony of Secretary Jacob J. Lew before the House Financial Services Committee. Available online: https://www.treasury.gov/press-center/press-releases/Pages/j12242.aspx (accessed on 12 June 2017). 
Merton, Robert C. 1973. The Theory of Rational Option Pricing. Bell Journal of Economic and Management Science 4: $141-83$.

Miller, Merton H. 1997. Merton Miller on Derivatives. New York: John Wiley.

Morrison, Alan D. 2005. Credit Derivatives, Disintermediation, and Investment Decisions. Journal of Business Available online: https:/ /www.jstor.org/stable/10.1086/427641?seq=1\#page_scan_tab_contents (accessed on 12 June 2017).

Smithson, Charles. 1998. Managing Financial Risk. New York: McGraw Hill.

Stegman, Michael. 2014. Presentation before a Bipartisan Policy Center Panel "Reigniting the Private Label Mortgage-Backed Securities Market". Available online: http://www.treasury.gov/press-center/pressreleases/Pages/j12634.aspx (accessed on 15 September 2014).

Still, Keith. 1997. The Economic Benefits and Risks of Derivative Securities. January/February 1997 Available online: https:/ / www.philadelphiafed.org/research-and-data/economists/sill (accessed on 12 June 2017).

Summers, Lawrence H. 1998. Testimony of Treasury Deputy Secretary Lawrence H. Summers to The Commodity Exchange Act and OTC derivatives before the Committee on Agriculture, Nutrition, and Forestry, U.S. Senate July 30, 1998. Available online: https://www.treasury.gov/press-center/press-releases/Pages/rr2616.aspx (accessed on 12 June 2017).

Sundaram, Rangarajan K. 2012. Derivatives in Financial Market Development. Available online: http:/ / people. stern.nyu.edu/rsundara/papers/RangarajanSundaramFinal.pdf (accessed on 12 June 2017).

(c) 2017 by the authors. Licensee MDPI, Basel, Switzerland. This article is an open access article distributed under the terms and conditions of the Creative Commons Attribution (CC BY) license (http://creativecommons.org/licenses/by/4.0/). 